Published in "Journal of Vertebrate Paleontology 27(3): 610-624, 2007"

which should be cited to refer to this work.

\title{
AN ABELISAUROID (DINOSAURIA: THEROPODA) FROM THE EARLY JURASSIC OF THE HIGH ATLAS MOUNTAINS, MOROCCO, AND THE RADIATION OF CERATOSAURS
}

\author{
RONAN ALLAIN, , ",2 RONALD TYKOSKI,' NAJAT AQUESBI, ${ }^{4}$ NOUR-EDDINE JALIL, ${ }^{1}$ MICHEL MONBARON," \\ DALE RUSSELL," and PHILIPPE TAQUET ${ }^{2}$ \\ 'Cadi Ayyad University, Faculty of Sciences Semlalia, Department of Earth Sciences, Laboratory of Paleontology and \\ Biostratigraphy, B.P. 2390, 40000 Marrakech, Morocco, ronan_allain@yahoo.fr; njalil@ucam.ac.ma; \\ ${ }^{2}$ Département Histoire de la Terre, Laboratoire de Paléontologie, Muséum National d'Histoire Naturelle, UMR 8569 CNRS, \\ 8 rue Buffon, 75005 Paris, France, taquet@mnhn.fr; \\ 'Museum of Nature \& Science, P.O. Box 151469, Dallas, Texas 75315-1469, U.S.A., rtykoski@natureandscience.org; \\ ${ }^{4}$ Ministry of Energy and Mines, Institut Agdal, B.P.6 208 Rabat, Morocco; \\ `Département de Géosciences, Université de Fribourg, Ch. du Musée 4, CH-1700 Fribourg, Switzerland, \\ michel.monbaron@unifr.ch; \\ ${ }^{6}$ North Carolina Museum of Natural Sciences, and Department of Marine, Earth and Atmospheric Sciences, \\ North Carolina State University, Box 8208, Raleigh, NC 27695, U.S.A., dale.russell@ ncmail.net.
}

\begin{abstract}
The fossil recorcl of abelisauroiclcarnivorous clinosaurs was previously restricted to Cretaceous secliments of Gondwana and probably Europe. The discovery of an incompletespecimen of a new basal abelisauroid. Berberosaurus liassicus. gen. et sp. nov.. is reported from the late Early Jurassic of Moroccan High Atlas Mountains. Phylogenetic analysis recovers Ceratosauroiclea and Coelophysoidea as sister lineages within Ceratosauria. and Berberosaurus as a basal abelisauroicl. Berberosaurus is the oldest known abelisauroiclancl extends the first appearance datum of this lineage by about 50 million years. The taxon bridges temporal. morphological. and phylogenetic gaps that have hitherto separated Triassic to Early Jurassic coelophysoids from Late Jurassic through Cretaceous ceratosauroids. The discovery of an African abelisauroicl in the Early Jurassic confirms at least a Gondwanan distribution of this group long before the Cretaceous.
\end{abstract}

\section{INTRODUCTION}

Continental strata of late Early Jurassic age are rare, and little is known of dinosaur evolution around the Early/Middle Jurassic boundary. There is almost no theropod record between the Pliensbachian and the Bajocian (ca. 195-175 Ma) (Weishampel et al., 2004). Thus, only four diagnosable theropod species have been described from these stages: the coelophysoid Segisaurus halli from the Pliensbachian-Toarcian of Arizona (Camp, 1936; Carrano et al., 2005), the enigmatic Cryolophosaurus ellioti from the Sinemurian-Pliensbachian of Antarctica (Hammer and Hickerson, 1994), and the probable spinosauroids Magnosaurus nethercombensis from the Aalenian-Bajocian (Huene, 1926, 1932), and 'Megalosaurus' hesperis (Waldman, 1974) from the Bajocian of England. This lack of data is unfortunate because phylogenetic hypotheses predict the diversification of some major saurischian clades (e.g., Tetanurae, Neosauropoda) during this interval (Wilson and Sereno, 1998; Sereno, 1999; Allain, 2002; Rauhut, 2003; Upchurch and Barrett, 2005).

For 6 years, several expeditions have collected well-preserved skeletal remains of dinosaurs from the late Early Jurassic Toundoute Series of the southern High Atlas Mountains in Morocco (Allain et al., 2004; Montenat et al., 2005). Two bone-beds, related to typical mud-flow deposition (Montenat et al., 2005), have yielded at least five partial skeletons of a primitive vulcanodontid sauropod, Tazoudasaurus naimi (Allain et al., 2004), a

\footnotetext{
"Corresponding author.
}

large carnivorous dinosaur of uncertain affinities, and a mediumsized theropod with ceratosaurian affinities. This article aims to describe the latter, and determines its phylogenetic relationships with other ceratosaurs (sensu Tykoski and Rowe, 2004) based in part upon a recent and thorough cladistic analysis of this lineage (Tykoski, 2005). The remains described here come from a single area of about $4 \mathrm{~m}^{2}$, and is $100 \mathrm{~m}$ apart from the site that yielded the holotypic specimen of Tazoudasaurus. Other remains of Tazoudasaurus including a 1-m long humerus have been found near the bones of Berberosaurus. Further work in the Toundoute Series raises the possibility of new finds in this area.

Institutional Abbreviations-MHNM, Muséum d'Histoire Naturelle de Marrakech. Morocco.

\section{SYSTEMATIC PALEONTOLOGY}

SAURISCHIA Seeley, 1887

THEROPODA Marsh, 1881

CERATOSAURIA Marsh, 1884 (sensu Rowe, 1989)

NEOCERATOSAURIA Novas, 1992 (sensu Holtz, 1994)

ABELISAUROIDEA (Bonaparte, 1991) Holtz, 1994 (sensu Sereno, 1998)

BERBEROSAURUS LIASSICUS, gen. et sp.nov.

Holotype-Associated postcranial material housed in the Muséum d'Histoire Naturelle de Marrakech, including a cervical vertebra (MHNM-Pt9); anterior part of the sacrum (MHNMPt23); the second left metacarpal (MHNM-Pt22); a right femur (MHNM-Pt19); the proximal end of the left tibia (MHNM-Pt21); 
the distal end of the right tibia (MHNM-Pt16); and the left fibula (MHNM-Pt20).

Referred Specimen-The proximal end of a right femur (MHNM-To1-218).

Etymology - Generic name is from the Berbers who live mainly in Morocco; "sauros" is Greek for lizard. Specific name from Lias, referring to the statigraphic epoch of the specimen.

Type Locality - Douar of Tazouda, near the village of Toundoute in the Province of Ouarzazate, High Atlas of Morocco.

Horizon and Age-Upper bone-bed ("Fossil locality B" of Allain et al., 2004) of the Toundoute continental series, middle to late Early Jurassic (Pliensbachian-Toarcian) (Montenat et al., 2005 ).

Diagnosis - Berberosaurus is characterized by the following unique combination of characters that nests the taxon among the abelisauroid ceratosaurs: highly pneumatic cervical vertebrae; anteroposteriorly short cervical vertebral centra with camerate internal structure; cervical neural spine anteroposteriorly short; ventral margin of sacral series strongly arched dorsally; transversely narrow sacral centra; proximal end of the second metacarpal deeply grooved ventrally; femoral anterior trochanter reaches proximally to mid-point of femoral head; large femoral trochanteric shelf; tibia with subtriangular distal profile; presence of an oblique ridge that proximally caps the medial sulcus of the fibula. Berberosaurus differs from Elaphrosaurus in: short cervical centra, pneumatic foramina on the cervical neural arch; from Ceratosaurus in: camerate structure of cervical vertebra, low and short neural spine of the cervical vertebra, femoral anterior trochanter reaches proximally to mid-point of femoral head; from Spinostropheus in: absence of the epipophysealprezygapophyseal lamina on the cervical neural arches, short cervical neural spine; from Abelisauria in: distal end of metacarpal with deep extensor pits; pronounced femoral trochanteric shelf.

Jenny and colleauges (1980) and Taquet (1984) briefly reported another theropod from the late Early Jurassic of the Moroccan High Atlas. This specimen comes from the Toarcian Wazzant Formation and is currently under preparation in the Muséum National d'Histoire Naturelle, in Paris. It differs clearly from Berberosaurusin its smaller size, the longer cervical vertebral centra, and the absence of a sulcus on the medial surface of the fibula.

\section{DESCRIPTION}

\section{Cervical Vertebra}

As with most of the holotypic material of Berberosaurus, the recovered cervical vertebra was affected by tectonism. A fault plane in which gypsum recrystallized crosses the vertebra lengthwise, but the specimen is not deformed and its left side is well preserved (Fig. 1). The distal tip of the postzygapophysis/ epipophysis complex and the ventral part of the posterior articular surface are broken. The centrum of this mid-cervicalvertebra is short with a length less than 1.5 times the diameter of the anterior articular surface (Table 1). The anterior surface is vertical and slightly concave, while the posterior articular surface dips slightly posteroventrally (Fig. 1A, B). The damaged posteroventral area of the centrum reveals at least two rounded internal cavities separated by a thin septum. These cavities are here interpreted as camerae. The ventral surface of the centrum is flat. The parapophyses are situated at the anteroventral corner of the centrum. Two pairs of deep, ovoid pleurocoels invade the body of the vertebra (Fig. 1C, D). The anterior pleurocoels are positioned dorsal to the parapophyses and excavate much of the centrum immediately behind the anterior articular surface. They are longer than tall. There is at least one additional, posteroventrally located foramen within the cervical anterior pleurocoel
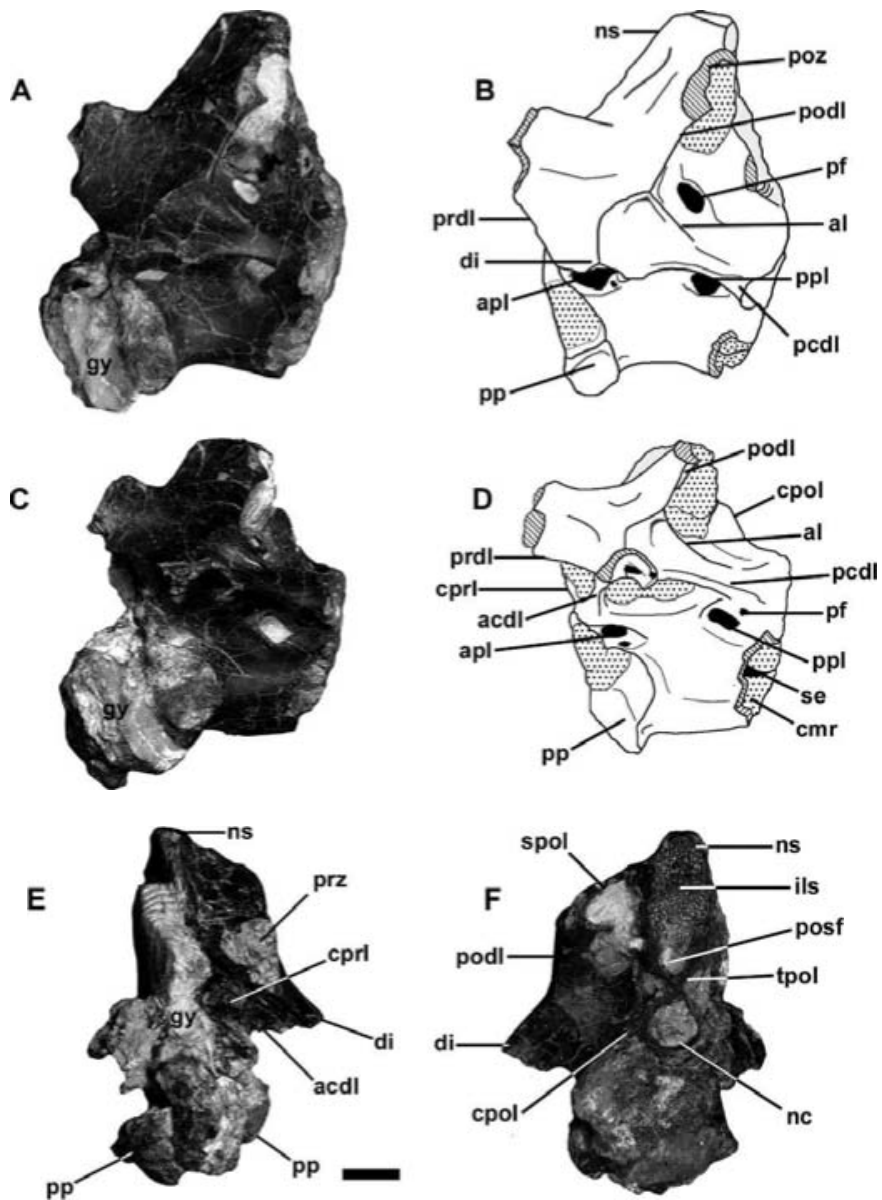

FIGURE 1. Cervical vertebra of Berberosaurus liassicus (MHNM-Pt9) in left lateral $(A, B)$, left ventrolateral $(C, D)$, anterior $(E)$, and posterior (F) views. Abbreviations: acdl, anterior centrodiapophyseal lamina; al, accesory lamina; apl, anterior pleurocoel; cmr, camera; cpol, centropostzygapophyseallamina; cprl, centroprezygapophyseal lamina; di, diapophysis; gy, gypsum; ils, interspinous ligament scar; ne, neural canal; ns, neural spine; pcdl, posterior centrodiapophyseal lamina; pf, pneumatic foramen; podl, postzygodiapophyseal lamina; posf, postspinal fossa; poz, postzygapophysis; pp, parapophysis; ppl, posterior pleurocoel; prdl, prezygodiapophyseal lamina; prz, prezygapophysis; se, septum; spol, spinopostzygapophyseal lamina; tpol, intrapostzygapophyseal lamina. Scale bar equals $1 \mathrm{~cm}$.

that accesses the centrum. The posterior pleurocoelis as long as tall. It is situated just below the suture between the centrum and the neural arch, $15 \mathrm{~mm}$ anterior to the posterior articular surface. Once again, at least one additional foramen pierces the posterior wall of the pleurocoelous fossa (Fig. 1D). The additional pneumaticforamina in both the anterior and posterior pleurocoels are unknown in other ceratosaurs, with the possible exception of Dilophosaurm (Tykoski, 2005). They are consistent with the camerate structure described above (Britt, 1997; Wedel, 2003). The suture between the centrum and neural arch is totally fused and indiscernible. The cervical neural arch is nearly two times taller than the centrum and bears the marks of extensive pneumatization. The prezygapophyses overhang the preceding cervical centrum whereas the postzygapophysesdo not extend posteriorly past the posterior articular surface of the centrum. The four principal diapophyseal laminae present in saurischian vertebrae (anterior centrodiapophyseal lamina, posterior centrodiapophyseal lamina, prezygodiapophyseal lamina, postzygodiapophyseal lamina) are present, in addition to the centro- 
TABLE 1. Measurements of Berberosaurus liassicus, gen et sp. nov.

\begin{tabular}{|c|c|}
\hline Element & Measurements \\
\hline \multicolumn{2}{|l|}{ Cervical vertebra (MHNM-Pt9) } \\
\hline Length of centrum & $53 \mathrm{e}$ \\
\hline Posterior height of centrum & 41 \\
\hline Posterior width of centrum & $35 \mathrm{e}$ \\
\hline $\begin{array}{l}\text { Anteroposterior length of the tip of the } \\
\text { neural spine }\end{array}$ & 16 \\
\hline \multicolumn{2}{|l|}{ Sacrum (MHNM-Pt23) } \\
\hline $\begin{array}{l}\text { Posterior width of centrum of the first } \\
\text { sacral vertebra }\end{array}$ & 27 \\
\hline \multicolumn{2}{|l|}{ Posterior height of centrum of the first } \\
\hline sacral vertebra & 43 \\
\hline Length of centrum of the second sacral vertebra & 64 \\
\hline \multicolumn{2}{|l|}{ Posterior width of centrum of the second } \\
\hline $\begin{array}{l}\text { sacral vertebra } \\
\text { Posterior heioht }\end{array}$ & 31,5 \\
\hline $\begin{array}{l}\text { Posterior height of centrum of the second } \\
\text { sacral vertebra }\end{array}$ & 55 \\
\hline Length of centrum of the first caudosacral & 70 \\
\hline Posterior width of centrum of the first & 37 \\
\hline Posterior height of centrum of the first & 66 \\
\hline \multicolumn{2}{|l|}{ Left metacarpal II (MHNM-Pt22) } \\
\hline Length & 78 \\
\hline Proximal width & 38 \\
\hline Distal width & 31 \\
\hline \multicolumn{2}{|l|}{ Right femur (MHNM-Pt19) } \\
\hline Length & $505 \mathrm{e}$ \\
\hline Proximal width & 141 \\
\hline Cicumference below the 4 th trochanter & 215 \\
\hline \multicolumn{2}{|l|}{ Distance from proximal end to top of } \\
\hline 4th trochanter & 240 \\
\hline Length of 4th trochanter & 100 \\
\hline \multicolumn{2}{|l|}{ Right femur (MHNM-Tol-218) } \\
\hline Proximal width & 114 \\
\hline \multicolumn{2}{|l|}{ Left tibia (MHNM-Pt16 and MHNM-Pt21) } \\
\hline Cicumference below the crista fibularis & 180 \\
\hline Distal width & 82 \\
\hline \multicolumn{2}{|l|}{ Left fibula (MHNM-Pt20) } \\
\hline Length & 447 \\
\hline Min. proximal width & 17 \\
\hline Proximal length & 98 \\
\hline Distal width & 22 \\
\hline Distal length & 38 \\
\hline
\end{tabular}

prezygapophyseal, centropostzygapophyseal, spinopostzygapophyseal and intrapostzygapophyseal laminae (Wilson, 1999). The diapophysis is directly dorsal to the parapophysis. It is laterally directed, ventrally pendant, and tapers distally (Fig. 1E). The ventral surface of the transverse process is perforated by a pneumatic foramen as in Carnotaurus and Masiakasaurus (Bonaparte et al., 1990; Carrano et al., 2002). The posterior wall of the foramen is formed by a small accessory lamina (Fig. 1B). The postzygodiapophyseal lamina is interrupted by a triangular fossa $20 \mathrm{~mm}$ from the tip of the diapophysis (Fig. 1A, B), much as in Spinostropheus (Sereno et al., 2004). A wide infrapostzygapophyseal fossa is present between the posterior centrodiapophyseal and the centropostzygapophyseal laminae (Fig. $1 F)$. Also as in Spinostropheus, a large foramen pierces the floor of the infrapostzygapophyseal fossa and opens into the neural canal (Fig. 1A). There is a triangular fossa between the centropostzygapophysealand intrapostzygapophyseal laminae, but it is unknown if it is perforated by foramina as in Masiakasaurus (Carrano et al., 2002). The neural spine is approximately centered over the centrum. It is slightly damaged distally, but it is anteroposteriorly short in comparison to cervical neural spines of coelophysoids and Ceratosaum. Posteriorly, within the large postspinal fossa, the neural spine bears scars for interspinous ligaments (Fig. 1F).

\section{Sacrum}

The partial sacral series is comprised of three fused centra with very incomplete neural arches (Fig. 2). The total sacral count is unknown. According to the positions of the preserved neural arch and sacral rib, and the lack of a true sacral rib on the largest centrum of the specimen, the specimen is interpreted as the first sacral, the second sacral, and the first caudosacral vertebrae (Fig. $2)$. The centra are firmly fused to one another. The trace of a suture is still visible between the centra of sacral 2 and caudosacral 1, but is nearly eliminated between the centra of sacrals 1 and 2. Although incomplete, the sacral series is strongly arched dorsally (Fig. 2A) to the same degree as in Ceratosaurus and Carnotaurus (Gilmore, 1920; Bonaparte et al., 1990). The centra are longer anteroposteriorly than tall dorsoventrally, and are transversely flattened as in abelisaurids and Ceratosaurus (Fig. 2B).

\section{Metacarpal}

The second left metacarpal was found near the fibula (Fig. 3). It is considerably longer than the second metacarpal of the abe-

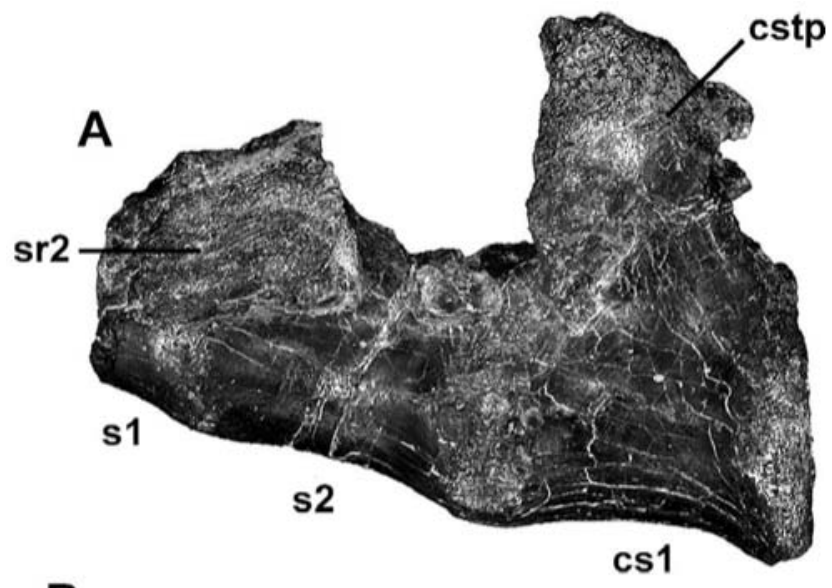

B
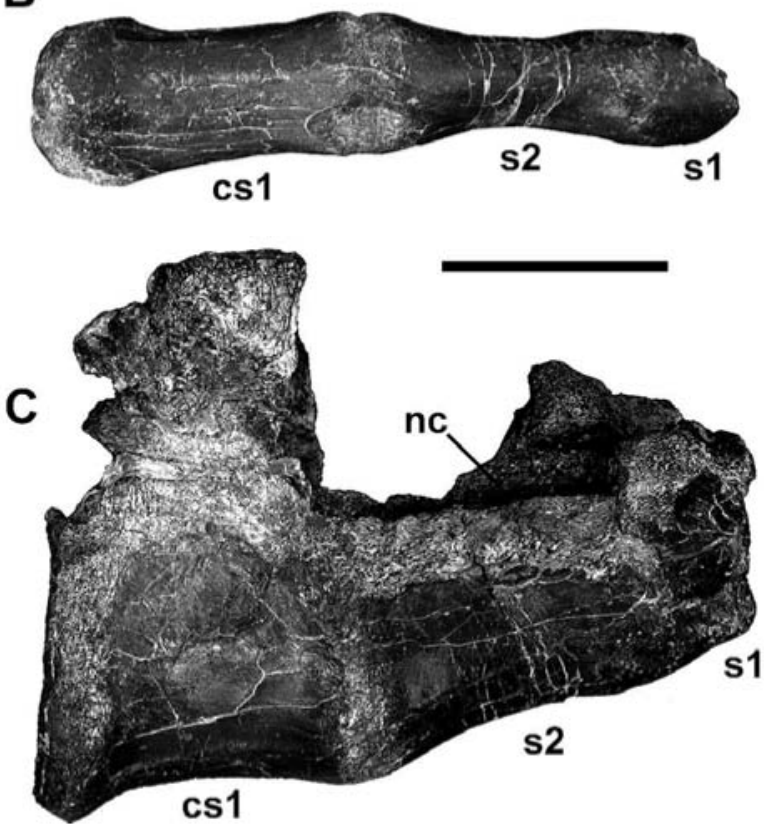

FIGURE 2. Sacrum of Berberosaurus liassicus (MHNM-Pt23) in left lateral (A), ventral (B), and right lateral (C) views. Abbreviations: csl, caudosacral vertebra 1 ; cstp, caudosacral transverse process; nc, neural canal; s1, sacral vertebra 1; s2, sacral vertebra 2; sr2, sacral rib 2. Scale bar equals $5 \mathrm{~cm}$. 


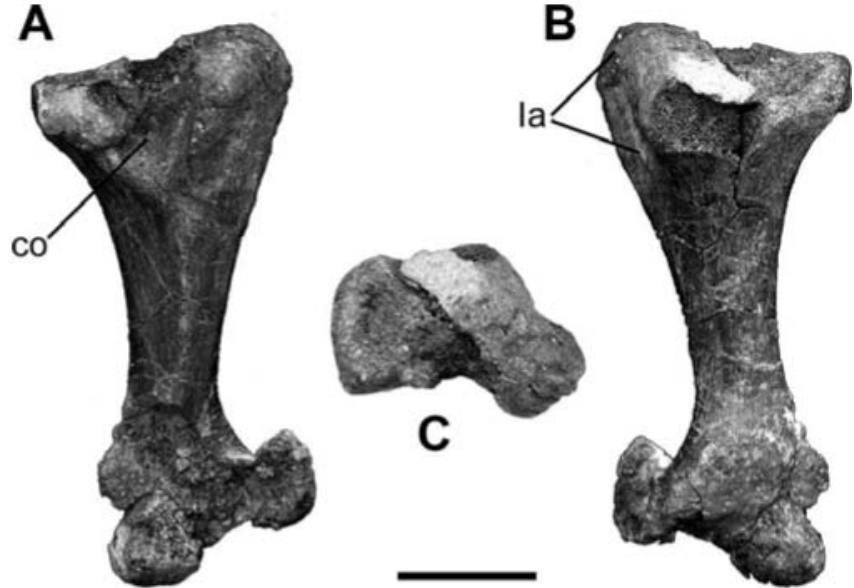

FIGURE 3. Second left metacarpal of Berberosaurus liassicus (MHNM-Pt22) in ventral (A), dorsal (B), and proximal (C) views. Abbreviations: co, ventral concavity; Ia, metacarpal I articular surface. Scale bar equals $2 \mathrm{~cm}$. lisaurid Aucasaurus (Coria et al., 2002). The proximal end is wider than the distal. It has an asymmetrical trapezoidal, proximal end (Fig. 3C), with proximal cotyles separated ventrally by a deep concavity (Fig. 3A). The medial cotyle is more developed and expanded mediolaterally and ventrally. The contact area between metacarpals I and II is restricted to the medial surface of the proximal base of the second metacarpal, unlike tetanurans. The shaft of the metacarpaltapers distally. As observed in distal view, the distal end is rotated about $45^{\circ}$ clockwise with respect to the proximal end. It is deeply grooved and asymmetrical, with the medial condyle more proximally-situated than the lateral (Fig. 3B).

\section{Femur}

The femur is the only element known from two specimens. A nearly complete right femur was found associated with the other bones described here (Fig. 4), and the proximal end of a right femur from a smaller individual (Fig. 5) was found at the site that yielded the holotypic material of Tazoudasaurus. Both femora are hollow. The proximal end of the larger and better-preserved femur was affected by tectonism and is now displaced $1 \mathrm{~cm}$ an-

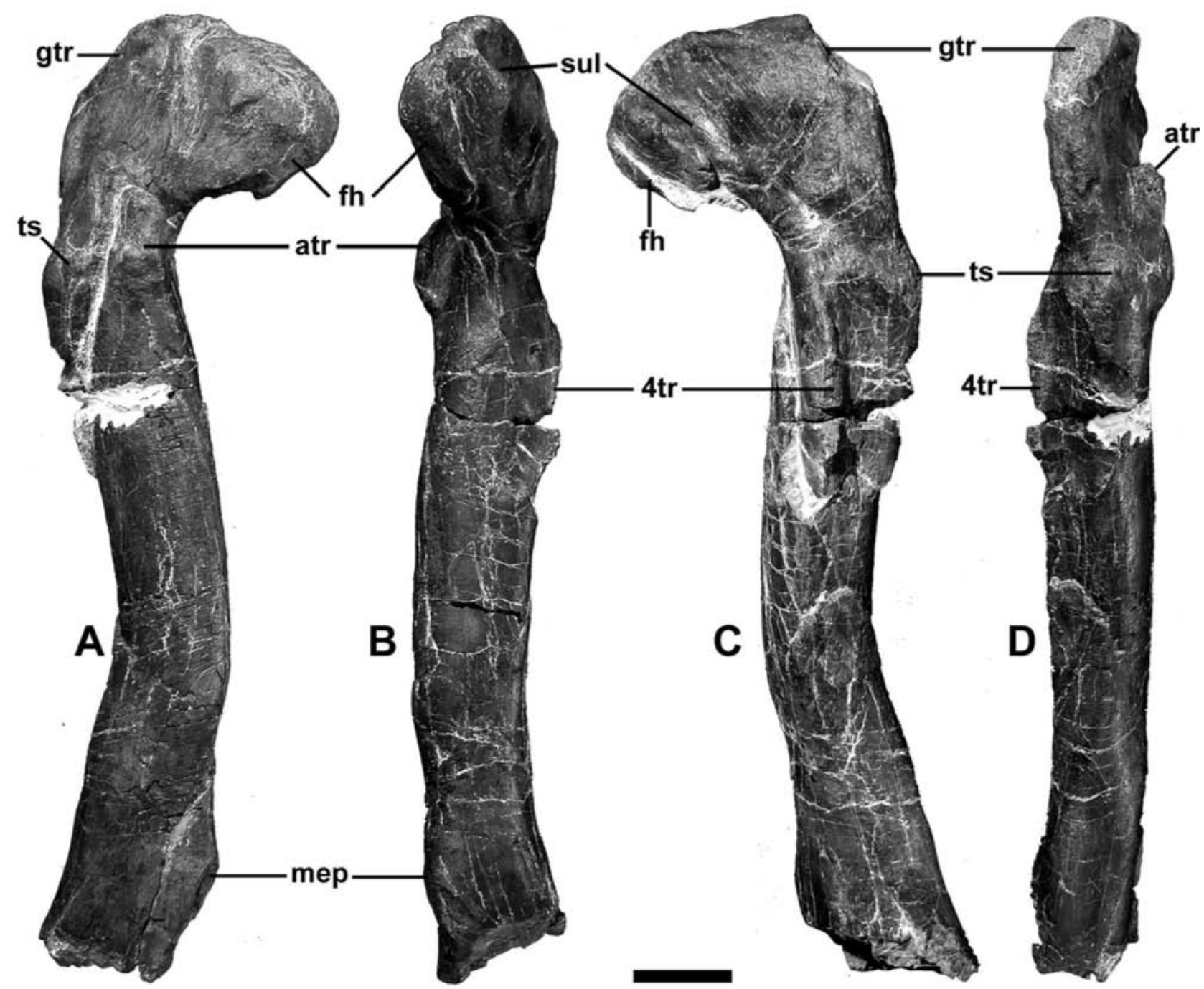

FIGURE 4. Right femur of Berberosaurus liassicus (MHNM-Pt19) in anterior (A), medial (B), posterior (C), and lateral (D) views. Abbreviations: atr, anterior trochanter; fh, femoral head; gtr, great trochanter; mep, medial epicondyle; sul, sulcus; tfc, tibiofibular crest; ts, trochanteric shelf; 4tr, fourth trochanter. Scale bar equals $5 \mathrm{~cm}$. 


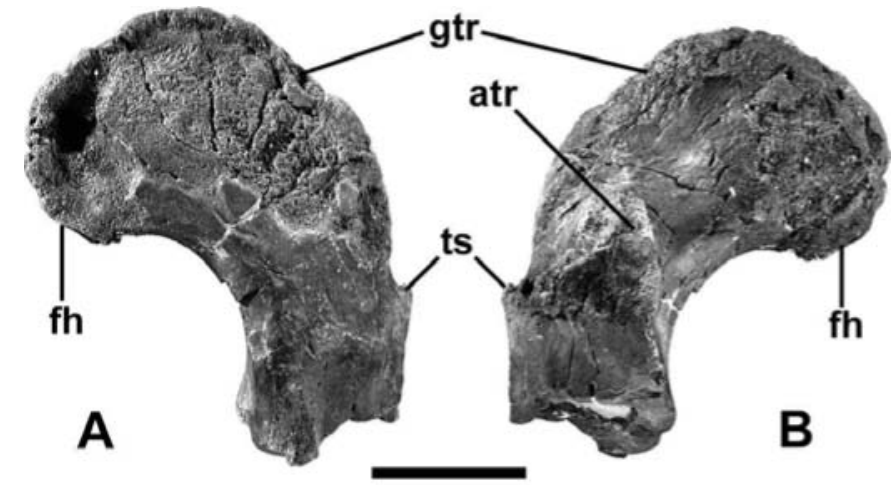

FIGURE 5. Proximal part of a right femur of Berberosaurus liassicus (MHNM-To2) in posterior (A), and anterior (B) views. Abbreviations: atr, anterior trochanter; fh, femoral head; gtr, great trochanter; ts, trochanteric shelf. Scale bar equals $5 \mathrm{~cm}$.

terolaterally. The shaft of the femur is sigmoid in anterior and posterior views (Figs. 4A, C), and relatively straight in lateral and medial views (Figs. 4B, D). Its cross-section is triangular at the level of the fourth trochanter and more rounded above the distal condyles. The femoral head is oriented anteromedially (Fig. 4B) and distally (Fig. 4A), and the proximal femur narrows anteroposteriorly toward the greater trochanter as in other nontetanuran theropods. A shallow groove runs mediolaterally across the middle of the proximal articular surface. The greater trochanter is confluent with the femoral head. The posterior surface of the proximal femur bears a well-defined proximomedially to distolaterally-trendingsulcus across the femoral neck (Fig. 4C), giving the femur a posteriorly hooked profile in proximal view. The morphology of the anterior trochanter of Berberosaurus is difficult to assess. The anterior trochanter is almost as stout as the spike-like version present in most coelophysoids, but it is more mediolaterally compressed and flange-like as in Ceratosaurus, Masiakasaurus, abelisaurids, and tetanurans. The anterior trochanter extends proximally as far as the level of the middle of the femoral head, and is set off from the femoral shaft by a weak cleft. The holotypic femur shows more of a mound than a shelf for the M. iliofemoralis insertion (Fig. 4). The referred femur exhibits a pronounced trochanteric shelf that originates on the anterior base of the anterior trochanter and extends distolaterally as in coelophysoids, and Ceratosaurus (Fig. 5 A-B). This suggests some degree of femoral dimorphism in Berberosaurus as in Coelophysis (Colbert, 1989; Raath, 1990), Ceratosaurus (Britt et al., 2002) and Masiakasaurus (Carrano et al., 2002). The fourth trochanter is strongly developed. It rises 19 $\mathrm{mm}$ above the posteromedial margin of the femur and extends approximately one-fifth the length of the bone (Fig. 4 B-D) to end $240 \mathrm{~mm}$ from the proximal articular surface. The holotypic femur preserves an enlarged medial epicondyle (Fig. 4A), but because its distal condyles are broken, it is impossible to know if this enlargement was as strongly developed as in abelisauroids.

\section{Tibia}

The tibiae are badly damaged, with only a part of the proximal left tibia (Figs. 6A-B) and the distal end of the right tibia preserved (Figs. 6C-E). The proximal piece was affected by tectonism. The proximal articular surface is missing, but the distal parts of the fibular crest and the cnemial crest are preserved (Fig. 6A). The fibular crest is well developed both distally and laterally and runs parallel to the main shaft axis (Fig. 6B). The cnemial crest curves laterally and the tibia has a hooked profile in proximal view. A nutrient foramen lies just posterodistal to the distal end of the cnemial crest (Fig. 6B). The distal end of the tibia is not fused with the astragalus despite the apparent maturity of the Moroccan specimen. The shaft of the tibia is thicker medially than laterally (Fig. 6E). The distal end of the right tibia is gently concave anteriorly and strongly convex posteriorly (Fig. $6 \mathrm{E})$. The lateral margin bears a scarred contact surface for the fibula. The lateral malleolus is broken distally. The oblique buttress that accommodated the ascending process of the astragalus slopes distomedially at about $33^{\circ}$ to the horizontal. The distal tibia is mediolaterally expanded, and has a subtriangular outline that contrasts with the more rectangular distal profile observed in coelophysoids.
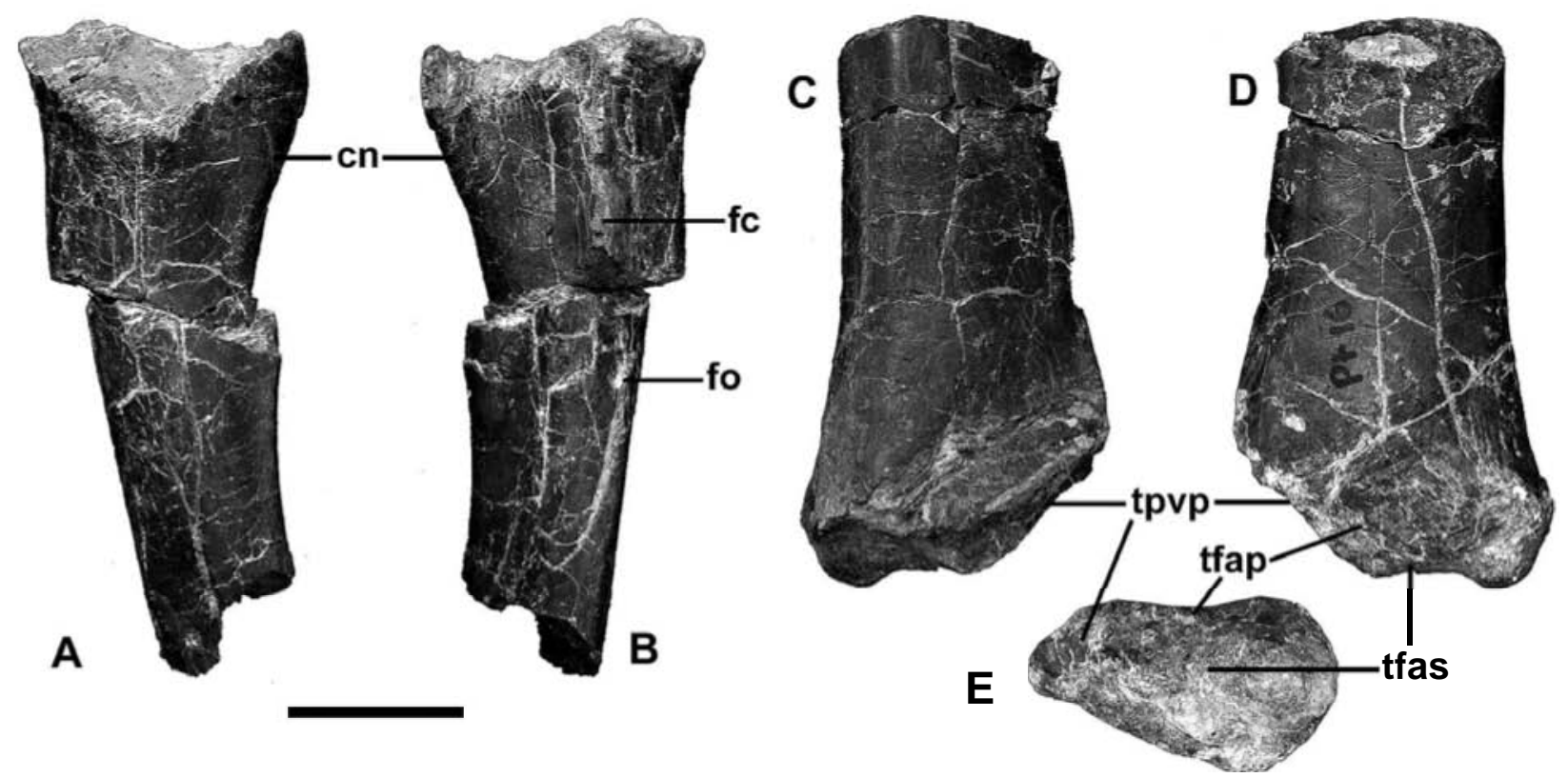

FIGURE 6. Tibiae of Berberosaurus liassicus. Proximal end of the left tibia (MHNM-Pt21) in medial (A), and lateral (B) views; distal end of the right tibia (MHNM-Pt16) in posterior (C), anterior (D), and distal (E) views. Abbreviations:cn, cnemial crest;fc, fibular crest;fo, nutrient foramen; tfap, tibial facet for ascending process of astragalus; tfas, tibial facet for astragalus ; tpvp, tibial posteroventral process. Scale bar equals $5 \mathrm{~cm}$. 
The left fibula is complete (Fig. 7). Its proximal end is anteroposteriorly expanded and bears a deep, proximodistallyelongate sulcus on its medial surface. This sulcus opens posteriorly and is capped proximally and anteriorly by a pronounced ridge that is also present in coelophysoids and Ceratosaurus (Fig. 7B). This ridge is raised from the remainder of the medial surface and has a rough texture. The shaft of the fibula tapers distally, except at the level of the insertion of the $M$. iliofibularis, which is marked by the presence of a large, anterolaterally-projecting process (Fig. 7A). The distal end of the fibula is slightly expanded both anteroposteriorly and mediolaterally. It is not co-ossified with the ascending process of the astragalus. The distal fibula has an anteromedial flange that may have partially overlapped the ascending process of astragalus as in some coelophysoids and Ceratosaurus.

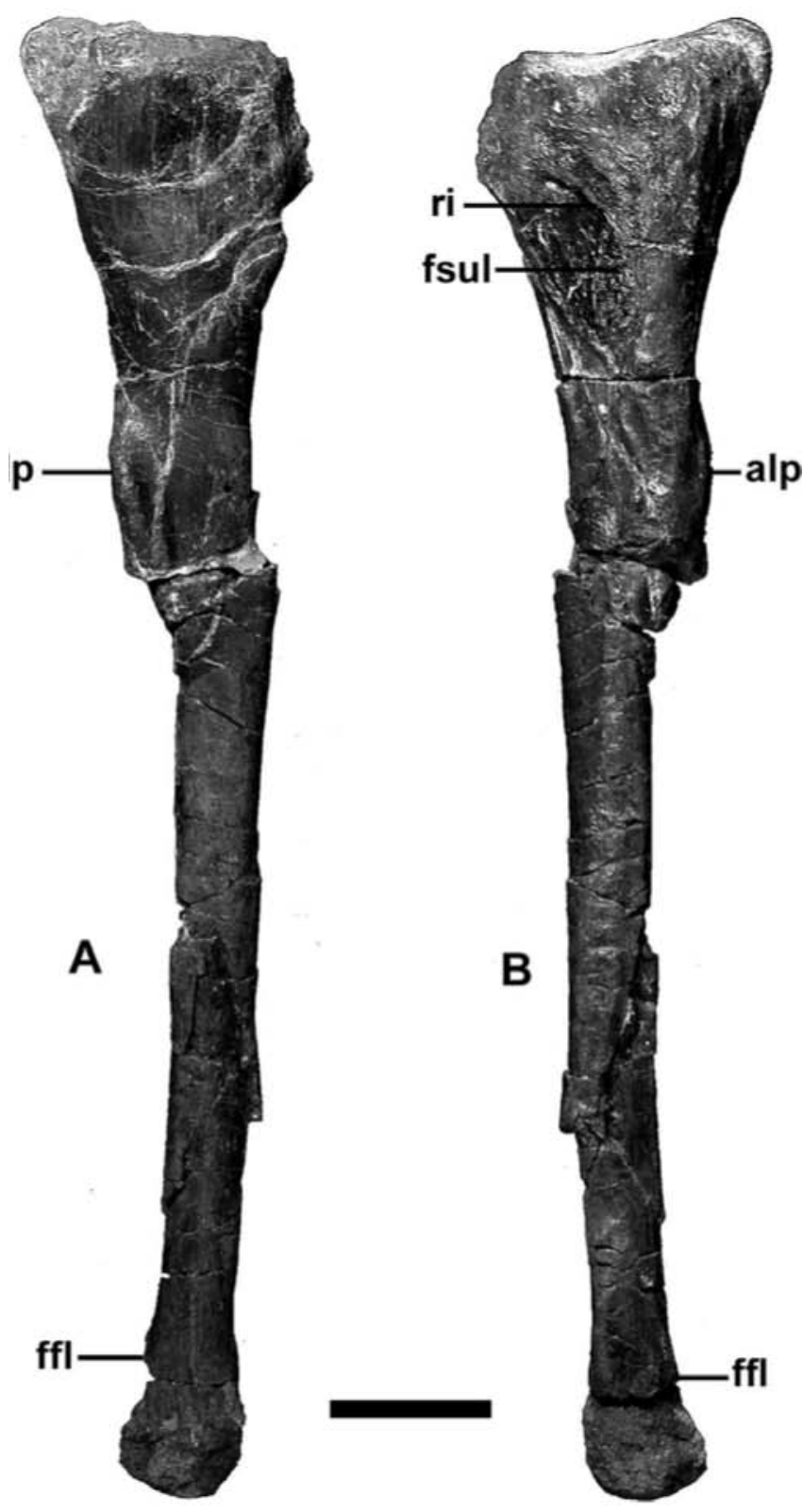

FIGURE 7. Left fibula of Berberosaurus liassicus (MHNM-Pt20) in lateral (A), and medial (B) views. Abbreviations:alp, anterolateral process;ffl, fibular flange; fsul, fibular sulcus; ri, ridge. Scale bar equals $5 \mathrm{~cm}$.

\section{Ontogenetic Status}

Recognition of the ontogenetic stage of Berberosaurus and other ingroup taxa is critical to proper comparisons and coding in our phylogenetic analysis (Carrano et al., 2005; Tykoski, 2005). Characters likely to be expressed only in later stages of ontogeny were treated as missing data in coelophysoid taxa represented by insufficiently mature specimens in our data matrix (see Tykoski [2005] for more details on the ontogenetic status of these various taxa). Three of the coelophysoid maturity-dependent characters listed by Tykoski (2005, Tab. 6) that were scored in Berberosaurus (see Appendix 2) were the absence of fusion between cervical ribs and their respective vertebral centra (character 130), no co-ossification between the astragalus and tibia (character 250), and no co-ossifcation between the astragalus and fibula (character 242). Given the w-ossification of these elements in relatively mature specimens of both coelophysoids and ceratosauroids it suggests that the holotype of Berberosaurus may not be a fully mature individual. Features that could reveal information regarding the relative maturity of the specimen include: the sacral centra exhibit full fusion to one another such that their sutures are nearly indiscernible; the femoral anterior trochanter is a mediolaterally compressed flange ( = aliform process) projecting anteriorly from the bone; the medial side of the proximal end of the fibula is excavated by a longitudinal groove, and the latter is overlapped by an oblique (posteroproximally to anterodistally oriented) ridge; and the fibula bears a medial flange that overlaps part of the ascending process of the astragalus. The balance of these observations suggests that the holotypic specimen of Berberosaurus is a subadult that died prior to reaching skeletal maturity. We also recognize that the quantitative ontogenetic analysis wnducted by Tykoski (2005) focused strictly upon coelophysoid taxa, and we acknowledge that Berberosaurusmay have had a different ontogenetic pattern than coelophysoids.

\section{Methods}

The phylogenetic position of the new taxon was evaluated by scoring four outgroup (Marasuchus, Scutellosaums, Lesothosaurus and Plateosaurus) and 30 ingroup taxa (Appendix 2) for 264 parsimony-informative characters (15 ordered, 249 unordered, see Appendix 1) (Tykoski, 2005). The data matrix was analyzed cladistically using PAUP* 4.0b10 (Swofford, 2002). Trees were rooted using the outgroup method with outgroup taxa set as successively paraphyletic taxa relative to the monophyletic ingroup. The analysis was conducted as a heuristic parsimony analysis with branch swapping by simple stepwise addition using the tree bisection-reconnection algorithm. A heuristic search was chosen because of large number of taxa and characters made more exhaustive search methods impractical. Multiple character states within a single taxon were treated as polymorphisms, as originally intended in the coding of the matrix.

\section{Results}

The analysis resulted in 21 equally most parsimonious hypotheses of phylogeny $(\mathrm{L}=636$, C.I. $=0.4890$, R.I.$=0.7289)$. A traditional Ceratosauria (including Coelophysoidea and Ceratosauroidea) was recovered as the sister stem-lineage to Tetanurae. The 21 trees differed only in the positions of the coelophysoids Zupaysaurus, Liliensternus, and the informally named "Shake-N-Bake" taxon. Berberosaurus was weakly supported as an abelisauroid more derived than Spinostropheus but outside a Xenotarsosaurus + Abelisauria clade in all the recovered trees (Fig. 8, see Appendix 3 for the distribution of unambiguous synapomorphies at each node of the strict consensus tree). 


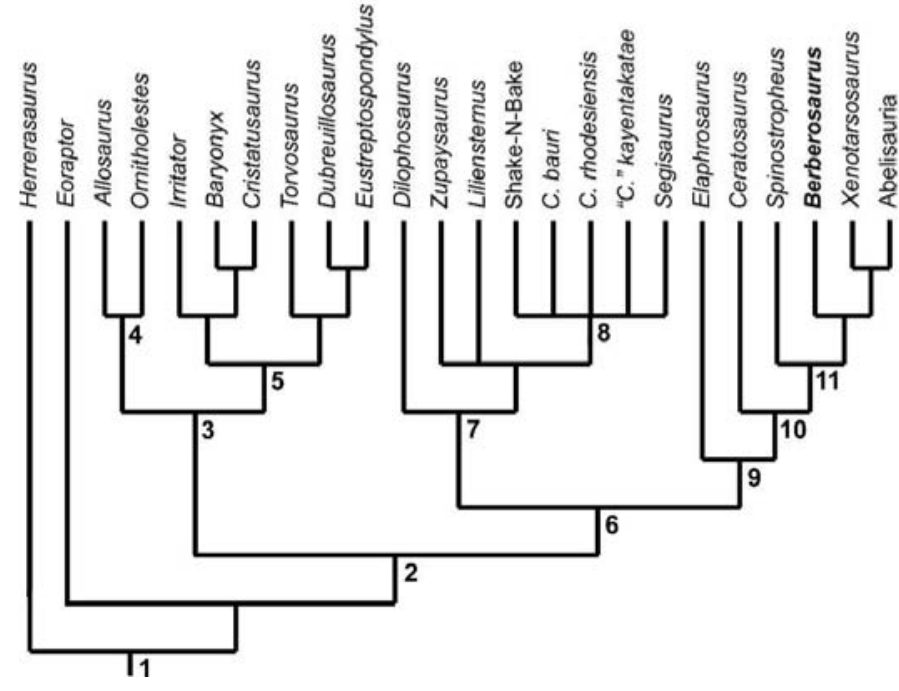

FIGURE 8. Phylogenetic relationships of Berberosaurus liassicus within Theropoda. Strict consensus tree of 21 most parsimonious trees $(\mathrm{L}=636$, C.I. $=0.4890$, R.I. $=0.7289)$. Clade numbers: 1, Theropoda; 2, Neotheropoda; 3, Tetanurae; 4, Avetheropoda; 5, Spinosauroidea; 6, Ceratosauria; 7, Coelophysoidea; 8, Coelophysidae; 9, Ceratosauroidea; 10, Neoceratosauria; 11, Abelisauroidea.

\section{DISCUSSION}

The discovery of Berberosaurus in late Early Jurassic sediments of Morocco has substantial phylogenetic and paleobiogeographic implications. Recent cladistic analyses of basal Theropoda have differed over whether the coelophysoid stemlineage was a member of Ceratosauria (Rowe, 1989; Sereno, 1999; Tykoski and Rowe, 2004; Tykoski, 2005), or was outside the Ceratosauria+Tetanurae clade (Carrano and Sampson, 1999;
Forster, 1999; Sampson et al., 2001; Carrano et al., 2002; Rauhut, 2003; Sereno et al., 2004). Critics of a 'traditional' Ceratosauria (including coelophysoids) pointed to the large stratigraphic gap between the youngest coelophysoids (Pliensbachian-Toarcian) and oldest 'true' ceratosaurs (Kimmeridgian-Tithonian), and suggested that there is less of a stratigraphic gap when ceratosauroids are linked with tetanurans than when they are linked with coelophysoids. Our cladistic analysis recovers a traditional, monophyletic Ceratosauria (Rowe, 1989) and places Berberosaurus as an abelisauroid more derived than the basal neoceratosaur Ceratosaurus from the Late Jurassic, and the abelisauroid Spinostropheus of Early Cretaceous age (Fig. 9; see Appendix 4 for phylogenetic definitions used here). Derived characters shared with other ceratosauriansinclude posterior pleurocoels in post-axial cervical centra, sacral centra exhibiting full fusion to one another such that sutures are nearly indiscernible by adulthood, and a proximal end of the fibula with an oblique ridge that overlaps the proximal part of the medial fibular groove (Appendix 3). Abelisauroid features present in Berberosaurus include the lateral surface of post-axial cervical arch pedicels pierced by foramina anteroventral to the postzygapophysis, post-axial cervical neural arches with pneumatic cavities lateral to the neural canal, and cervical neural arch surfaces ventral to transverse processes pierced by multiple pneumatic foramina.

Bevbevosaurus is the oldest known abelisauroid, and it represents a considerable temporal range extension for a lineage whose other members are Neocomian (Sereno et al., 2004) or younger (Tykoski and Rowe, 2004), except if the material from Tendaguru, recently described by Rauhut (2005), is proved by a future phylogenetic analysis to be an abelisauroid. Its presence implies a previously unrecognized diversification of ceratosauroids by the Early Jurassic (Fig. 9). Bevbevosaurus essentially closes the stratigraphic gap separating coelophysoids and ceratosauroids, as predicted by cladistic phylogenetic hypothesis. Abelisauroids, and more especially Abelisauridae were used as key evidence for faunal exchanges between Gondwanan landmasses (Sampson et al., 1998; Sereno et al., 2004) and between

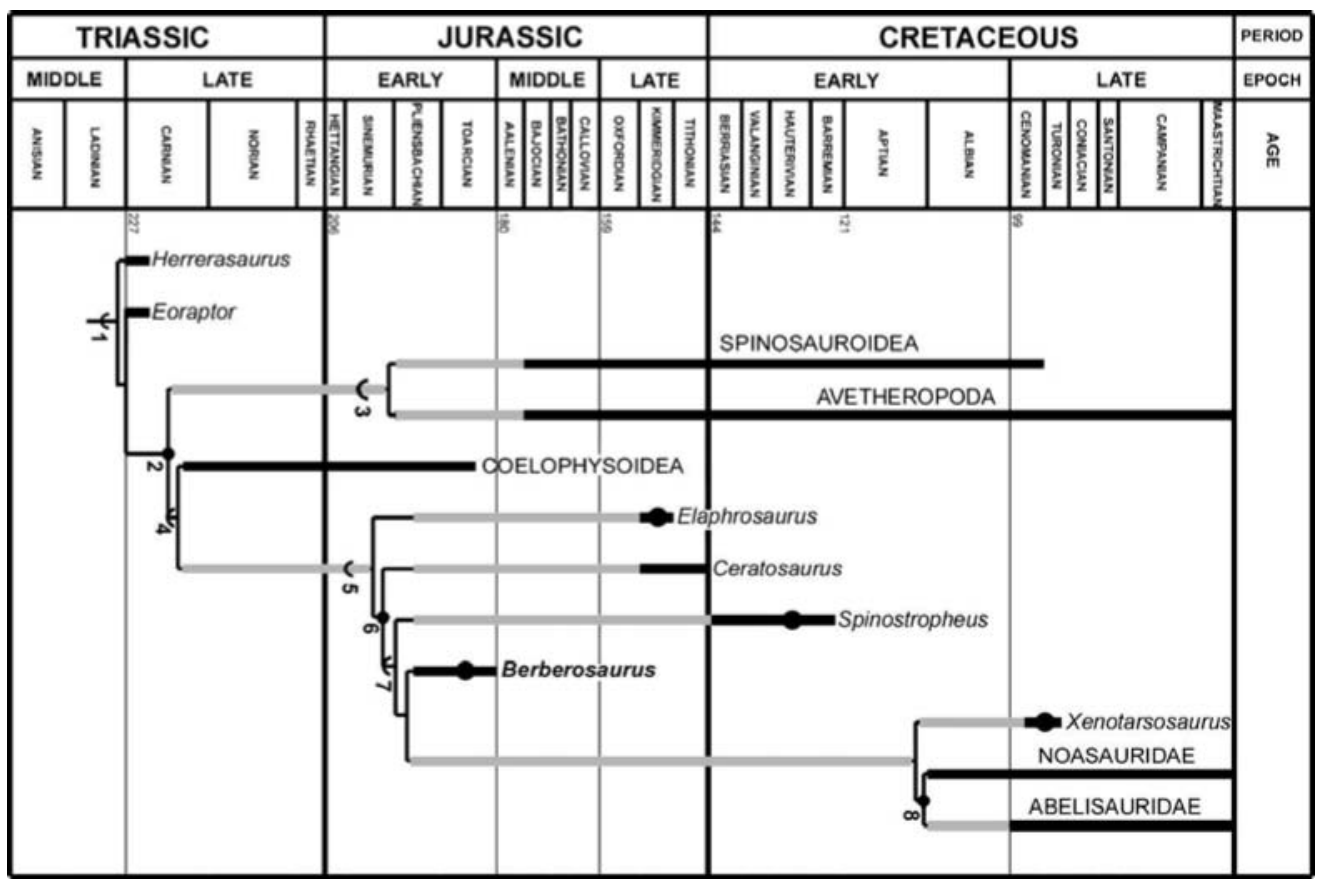

FIGURE 9. Stratigraphically calibrated phylogeny of Ceratosauria and basal Theropoda, based on the strict consensus tree of the current study. Clade numbers: 1, Theropoda; 2, Neotheropoda; 3, Tetanurae; 4, Ceratosauria; 5, Ceratosauroidea; 6, Neoceratosauria; 7, Abelisauroidea; 8, Abelisauria. Arcs indicate stem-names, solid circles indicate node-names. Black lines indicate known stratigraphic ranges and grey lines indicate inferred ghost lineages. 
Gondwana and Europe (Buffetaut et al., 1988; Le Loeuff, 1991), because their record was restricted to Late Cretaceous strata of the southern continents and probably Europe (Weishampel et al., 2004). Berberosaurus reveals that basal abelisauroids were already diversified by the Early Jurassic, and they were probably distributed between Africa, South America, Madagascar, India and Europe long before the Cretaceous and the fragmentation of Gondwana. This scenario is consistent with the pan-Gondwanan hypothesis suggested by previous authors (Lamanna et al., 2002; Sereno et al., 2004), but with faunal exchanges among Gondwanan landmasses occurring between the Early Jurassic and the Early Cretaceous. It also suggests that fossils of basal abelisauroids should be present in Early Jurassic sediments across Pangea, given that Laurasia and Gondwana were still connected through that time. This discovery emphasizes how poorly known is the origin and early evolution of ceratosauroids, and highlights the importance of finding and describing new Early and Middle Jurassic theropod remains in order to document the evolutionary history of Theropoda across the Triassic-Jurassic faunal transition.

\section{ACKNOWLEDGMENTS}

This work was supported by the Ministry of Energy and Mines of Morocco, the Committee for Research and Exploration of the National Geographic Society (Grant 7798-05), the Agence Universitaire de la Francophonie and the Fondation des Treilles. We thank R. Vacant and P. Richir for helping to the preparation of the material,P. Loubry for photographs, J. Wilson and K. Padian for their critical and helpful comments, and all the participants in the DinoAtlas Project: P. Richir, M. Rouchdy, C. Montenat, M. M'Ghari, A. Faskaoune, M. Fontaine, S. Hervet, S. Ladeveze, A. Aumont, C. Sagne, and the students from Marrakech University.

\section{LITERATURE CITED}

Allain, R. 2002. Discovery of megalosaur (Dinosauria, Theropoda) in the Middle Bathonian of Normandy (France) and its imylications for the phylogeny of basal Tetanurae. Journal of Vertebrate Paleontology 22:548-563.

Allain, R., N. Aquesbi, J. Dejax, C. Meyer, M. Monbaron, C. Montenat, P. Richir, M. Rochdy, D. A. Russell, and P. Taquet. 2004. A basal sauropod dinosaur from the Early Jurassic of Morocco. Comptes Rendus Palevol 3:199-208.

Bonaparte, J. F. 1991. The Gondwanian theropod families Abelisauridae and Noasauridae. Historical Biology 5:1-25.

Bonaparte, J. F., F. E. Novas, and R. A. Coria. 1990. Camotaurus sastrei Bonaparte, the horned, lightly built carnosaur from the middle Cretaceous of Patagonia. Contributions in Science, Natural History Museum of Los Angeles County 416:1-42.

Britt, B. B. 1997. Postcranial pneumaticity; pp. 590-593 in P. J. Currie and K. Padian (eds.), Encyclopedia of Dinosaurs. Academic Press, San Diego, California.

Britt, B. B., D. J. Chure, T. R. Holtz, C. A. Miles, and K. L. Stadtman. 2000. A reanalysis of the phylogenetic affinities of Ceratosaurus, (Theropoda, Dinosauria) based on new specimen from UT, CO, and WY. Journal of Vertebrate Paleontology 20:32A.

Buffetaut, E., P. Mechin, and A. Mechiin-Salessy. 1988. Un dinosaure thkropode d'affinitks gondwaniennes dans le Crétacé supérieur de Provence. Comptes Rendus de l'Académie des Sciences de Paris 306:153-158.

Camp, C. L. 1936. A new type of small bipedaldinosaur from the Navajo Sandstone of Arizona. University of California Publications in Geological Sciences 24:39-53.

Carrano, M. T., and S. D. Sampson. 1999. Evidence for a paraphyletic 'Ceratosauria' and its imvlications for theroyod dinosaur evolution. Journal of Vertebrate Paleontology 19:36A.

Carrano, M. T., S. D. Sampson, and C. A. Forster. 2002. The osteology of Masiakasaurus knopfleri, a small abelisauroid (Dinosauria: Theropoda) from the Late Cretaceous of Madagascar. Journal of Vertebrate Paleontology 22:510-534.

Carrano, M. T., J. H. Hutchinson, and S. D. Sampson. 2005. New infor- mation on Segisaurus halli, a small theropod dinosaur from the Early Jurassic of Arizona. Journal of Vertebrate Paleontology 25: 835-849.

Colbert, E. H. 1989. The triassic dinosaur Coelopophysis. Museum of Northern Arizona Bulletin 57:1-160.

Coria, R. A., L. M. Chiappe, and L. Dingus. 2002. A new close relative of Camotaurus sastrei Bonaparte, 1985. (Theropoda: Abelisauridae) from the Late Cretaceous of Patagonia. Journal of Vertebrate Paleontology 22:460-465.

Forster, C. A. 1999. Gondwanan dinosaur evolution and biogeographic analysis. Journal of African Earth Sciences 28:169-185.

Gilmore, C. W. 1920. Osteology of the carnivorous Dinosauria in the United States National Museum, with special reference to the genera Antrodemus (Allosaurus) and Ceratosaurus. Bulletin of the United Sates National Museum 110:1-154.

Hammer, W. R., and W. J. Hickerson. 1994. A crested theropod dinosaur from Antarctica. Science 264:828-830.

Huene, F. von 1926. The carnivorous Saurischia in the Jura and Cretaceous formations, principally in Europe. Revista del Museo de la Plata 29:35-167.

Huene, F. von 1932. Die fossile Reptil-Ordnung Saurischia, ihre Entwicklung und Geschichte. Monographien zur Geologie und Palaeontologie 4:1-361.

Jenny, J., C. Jenny-Deshussess, A. Le Marrec, and P. Taquet. 1980. Découvertes d'ossements de Dinosauriens dans le Jurassique inférieur (Toarcien) du Maroc. Comptes Rendus de l'Académie des Sciences de Paris 290:839-842.

Lamanna, M. C., R. D. Martinez, and J. B. Smith. 2002. A definitive abelisaurid theropod dinosaur from the early Late Cretaceous of Patagonia. Journal of Vertebrate Paleontology 22:58-69.

Le Loeuff, J. 1991. The Campano-Maastrichtian vertebrate faunas from southern Europe and their relationships with other faunas in the world : palaeobiogeographicalimplications. Cretaceous Research 12:93-114.

Marsh, O. C. 1881. Principal characters of American Jurassic dinosaurs. Part V. American Journal of Science 21:417-423.

Marsh, O. C. 1884. Principal characters of American Jurassic dinosaurs. Part VIII. The Order Theropoda. American Journal of Science 27: 329-340.

Montenat, C., M. Monbaron, R. Allain, N. Aquesbi, J. Dejax, J. Hernandez, D. Russell, and P. Taquet. 2005. Stratigraphie et paléoenvironnement des dépôts volcano-dktritiques a dinosauriens du Jurassique inférieur de Toundoute (Province de Ouarzazate, HautAtlas-Maroc). Eclogae Geologicae Helvetiae 98:261-270.

Novas, F. E. 1992. La evolución de los dinosaurios carnívoros; pp. 123-163 in J. L. Sanz, and A. Buscalioni (eds.), Los Dinosaurios y su Entorno Biótico. Actas II Curso de Paleontología en Cuenca. Instituto "Juan de Valdes", Ayuntamiento de Cuenca, España.

Raath, M A. 1990. Morphological variation in small theropods and its meaning in systematics: evidence from Syntarsus rhodesiensis; pp. 91-105 in K. Carpenter, and P. J. Currie (eds.), Dinosaur Systematics: Approaches and Perspectives. Cambridge University Press, New York.

Rauhut, O. W. M. 2003. The interrelationships and evolution of basal theropod dinosaurs. Special Papers in Palaeontology 69:1-215.

Rauhut, O. 2005. Post-cranial remains of 'coelurosaurus' (Dinosauria, Theropoda) from the Late Jurassic of Tanzania. Geological Magazine 142:97-107.

Rowe, T. 1989. A new species of the theropod dinosaur Syntarsus from the Early Jurassic Kayenta Formation of Arizona. Journal of Vertebrate Paleontology 9:125-136.

Sampson, S. D., M. T. Carrano, and C. A. Forster. 2001. A bizarre predatory dinosaur from the Late Cretaceous of Madagascar. Nature 409:504-506.

Sampson, S. D., L. M. Witmer, C. A. Forster, D. W. Krause, P. M. O'Connor, P. Dodson, and F. Ravoavy. 1998. Predatory dinosaur remains from Madagascar: implications for the Cretaceous biogeography of Gondwana. Science 280:1048-1051.

Seeley, H. G. 1887. On the classification of the fossil animals commonly named Dinosauria. Proceedings of the Royal Society of London 43:165-171.

Sereno, P. C. 1999. The evolution of dinosaurs. Science 284:2137-2147.

Sereno, P. C., J. A. Wilson, and J. L. Conrad. 2004. New dinosaurs link southern land-masses in the mid-Cretaceous. Proceedings of the Royal Society of London B 271:1325-1330. 
Swofford, D. L. 2002. PAUP*. Phylogenetic Analysis Using Parsimony (*and Other Methods). Version 4.0 b10. Sinauer Associates, Sunderland, Massachusetts.

Taquet, P. 1984: Two new Jurassic specimens of Coelurosaurs (Dinosauria). The beginnings of birds, Eichstätt, 1984.

Tykoski, R. S. 2005. Anatomy, ontogeny, and phylogeny of coelophysoid theropods. Ph.D. dissertation, The University of Texas at Austin, Austin, Texas, 553 pp.

Tykoski, R. S., and T. Rowe. 2004. Ceratosauria; pp. 47-70 in D. B. Weishampel, P. Dodson, and H. Osmólska (eds.), The Dinosauria Second Edition. University of CaliforniaPress, Berkeley,California.

Upchurch, P., and P. M. Barrett. 2005. Phylogenetic and taxic perspectives on sauropod diversity; pp. 104-124 in K. A. Curry Rogers and J. A. Wilson (eds.), The Sauropods Evolution and Paleobiology. University of California Press, Berkeley, California.

Waldman, M. 1974. Megalosaurids from the Bajocian (Middle Jurassic) of Dorset. Palaeontology 17:325-339.

Wedel, M. J. 2003. The evolution of vertebral pneumacity in sauropod dinosaurs. Journal of Vertebrate Paleontology 23:344-357.

Weishampel, D. B., P. M. Barrett, R. A. Coria, J. Le Loeuff, X. Xing, Z. Xijin, A. Sahni, E. Gomani, and C. R. Noto. 2004. Dinosaur distribution; pp. 517-606 in D. B. Weishampel, P. Dodson, and H. Osmólska (eds.), The Dinosauria. Second Edition. University of California Press, Berkeley, California.

Wilson, J. A., and P. C. Sereno. 1998. Early evolution and higher-level phylogeny of sauropod dinosaurs. Society of Vertebrate Paleontology Memoir 5:1-68.

Wilson, J. A. 1999. A nomenclature for vertebral laminae in sauropods and other saurischian dinosaurs. Journal of Vertebrate Paleontolow 19:639-653.

Submitted November 15, 2006; accepted February 11,2007.

APPENDIX 1. List of characters used in phylogenetic analysis.

Characters ordered by anatomical region. UO: unordered multistate character; 0 : ordered multistate character.

1. Craniofacial bones (i.e., maxilla, jugal, quadratojugal, nasal) relatively smooth (0), or sculptured (1) (Novas, 1997).

2. Skull length $<3$ times $(0)$, or $>3$ times (1) posterior skull height (height $=$ articular condyle of quadrate to dorsal-most edge of parietal) (Forster, 1999; Sereno, 1999a).

3. Orbit approximately circular (0), or keyhole-shaped,with narrower ventral end (1) (Gauthier, 1986)

4. Orbit anteroposterior diameter $>(0)$, or $<(1)$ internal antorbital fenestra length (Holtz 1998).

5. Internal antorbital fenestra anteroposterior length $<25 \%(0)$, or $\geq 25 \%$ maximum skull length (Rowe, 1989 ).

6. Premaxilla body (excludes maxillary and nasal processes) height 1 length ratio $\leq 1.25(0)$, or $>1.25$ (1) (modified from Holtz 1994,1998; Sampson et al., 1998; Carrano et al., 2002).

7. Premaxilla lateral surface penetrated by many neurovascular foramina $(0)$, or few or none (1).

8. Premaxilla nasal process comprises $>50 \%(0)$, or $\leq 50 \%$ (1) of external naris anterodorsal border (Holtz, 1998).

9. Premaxillary tooth row terminates ventral to (0), or entirely anterior to (1) external naris (Sereno, 1999a).

10. Premaxillary lateral surface dorsal to second tooth position smooth (0), or marked by small pit at base of nasal process (1).

11. Maxillary process of premaxilla dorsoventrally wide and plate-like (0), or narrow and rod-like (modified from Gauthier, 1986; Rauhut, 2003).

12. Maxillary process of premaxilla contacts nasal (0), or does not contact nasal,allowing maxilla to contribute to rim of external naris (1) (modified from Gauthier, 1986; Holtz, 1998; Rauhut, 2003).

13. Maxillary process of premaxilla anteroposterior length $\geq(0)$, or much <(1) length of alveolar body of premaxilla (modified from Holtz, 1998)

14. Maxillary process of premaxilla ventral margin unexpanded $(0)$, or with posteroventrally directed flange, resulting in appearance of "forked" premaxilla (1) (Rauhut, 2003).

15. Palatal process of premaxilla a pronounced shelf $(0)$, or only a blunt ridge or absent (1) (Sampson et al., 1998).

16. Premaxilla and maxilla with strong, immobile articulation (0), or are only loosely articulated with each other (1) (Sereno, 1999a).
17. Premaxilla and maxilla in contact at alveolar margins (0), or alveolar margins do not contact (1).

18. Premaxilla-maxillasuture uninterrupted $(0)$, or interrupted by subnarial foramen (1) (Gauthier 1986, Novas, 1992; Sereno et al., 1993; Coria and Salgado, 1998).

19. Anterodorsal margin of maxilla is linear or anterodorsally convex $(0)$, or anterodorsally concave (1) in lateral view (modified from Holtz, 1998).

20. Transition along dorsal border of maxilla from anterior process to dorsal process is gradual, smoothly curved (0), or abrupt to angular (1) in lateral view.

21. Dorsal process of maxilla axis angles posterodorsally between $35^{\circ}$ and $50^{\circ}(0)$, or $\leq 35^{\circ}(1)$, or $>50^{\circ}$ (2) from horizontal. (UO)

22. Dorsal process of maxilla long and contacts lacrimal (0), or with very short posterior component that does not contact lacrimal (1) (Coria et al., 2002).

23. Anterior process of maxilla length $510 \%(0)$, or $10 \%<25 \%(1)$, or $225 \%$ (2) total maxilla length. (UO)

24. Ratio of dorsoventral height of proximalend of anterior process of maxilla versus height of alveolar ramus of maxilla at first alveolus posterior to rim of internal antorbital fenestra $<1.0(0)$, or 21.0 (1)

25. Anterior tip of maxillary alveolar margin oriented approximately horizontal (0), or curves sharply mediodorsally (1) (modified from Rowe, 1989).

26. Maxillary first alveolus opens ventrally (0), or anteroventrally (1) (Rowe, 1989).

27. Maxilla with $<20(0)$, or 220 (1) teeth/alveoli in adults

28. Maxilla with $>10(0)$, $\leq 10$ teethlalveoli in adults (modified from Carrano et al., 2002).

29. Maxillary tooth row ends posterior or ventral (0), or anterior (1) to anterior rim of orbit (Gauthier 1986).

30. Ventral margin of maxillary antorbital fossa indistinct or marked by low rounded ridge $(0)$, or sharply marked by alveolar ridge that parallels alveolar margin (1)

31. Maxillary antorbital fossa anterior to internal antorbital fenestra broad (0), or narrow, extends little beyond rim of internal antorbital fenestra (1) (Sereno et al., 1994; Forster, 1999).

32. Anterior margin of maxillary antorbital fossa rounded (0), or squared, with angular corners and nearly straight anterior border (1) (Rauhut, 2003)

33. Maxillary antorbital fossa ventral to internal antorbital fenestra broad (0), or very narrow or obscured in lateral view (1) (Novas 1989; Carrano et al., 2002).

34. Promaxillary fenestra of maxilla absent $(0)$, or present, clearly visible in lateral view (1), or present and concealed from lateral view by lateral lamina of maxillary antorbital fossa (2) (modified from Holtz, 1994,1998). (0)

35. Medial lamina of dorsal process of maxilla smooth and continuous (0), or with deep accessory pneumatic excavation (1) (Carrano et al., 2002)

36. Medial lamina of maxillary antorbital fossa solid (0), or perforated by maxillary fenestra (1) (Gauthier, 1986).

37. Anteromedial/palatal process of maxilla short, protrudes little beyond maxilla's anterior process $(0)$, or is long, finger-like projection (1), or long, dorsoventrally tall, mediolaterally narrow, and platelike (2). (UO)

38. Medial surface of anteromedial process of maxilla smooth (0), or bears longitudinal ridges (1) (Sereno et al., 1998).

39. Nasals are separate (0), or partially fused, either at anterior end or within median crests or prominences(1), or fused over entire length (2) in adults (modified from Sereno, 1999a). (0)

40. Lateral margin of nasal simple (0), or bears low expanded ridge (1), or forms part of parasagittal crest rising from dorsolateral margin of skull (2), or forms all of thin parasagittal crest (3) (modified from Holtz, 1998)

41. Dorsal surfaces of nasals relatively smooth (0), or rugose, with heavy pitting and sculpturing (1) (Holtz, 1998).

42. Lateral or posterolateral surface of nasal solid (0), or perforated by pneumatic foramen/foramina (1) (Forster, 1999).

43. Lateral surface of anterior end of nasal along margin of external naris relatively flat $(0)$, or with concave fossa (1), or with laterally convex hood covering posterior part of external naris (2) (Carrano et al., 2002). (UO)

44. Nasal excluded from (0), or contributes to border of (1) antorbital cavity (Holtz, 1998). 
45. Frontals anteroposteriorly short and approximately rectangular(0), or elongated and triangular (1) in dorsal view (Holtz, 1994).

46. Frontals remain separate (0), or indistinguishably fuse to each other (1) in adults (Holtz, 1998).

47. Frontals relatively flat (0), or contribute to dorsal skull roof prominences (i.e. horns, knobs, bosses) (1), or bear large, laterally positioned supraorbital horns (2) (Coria et al., 2002). (0)

48. Frontals and parietals remain separate (0), or fuse (1) in adults (Holtz, 1998; Forster, 1999; Sereno, 1999a).

49. Frontal-parietal contact area relatively flat (0), or with median fossa in saddle-shaped depression (1) (Sampson et al., 1998).

50. Dorsal surface of parietal relatively flat (0), or with transversely thickened sagittal crest between supratemporal fenestrae (1) (Novas, 1989; Holtz, 1998).

51. Parietal nuchal crest relatively small, thin (0), or greatly enlarged and elevated (1) (Forster, 1999; Sereno, 1999a).

52. Lacrimal blocky or triangular (0), or an inverted L-shape (1) in lateral view (modified from Rauhut, 2003).

53. Lacrimal dorsoventrallyshorter than orbit and fails to reach level of orbit's ventral rim (0), or as tall or subequal to height of orbit with ventral end that reach level of orbit's ventral rim (1) (modified from Rauhut, 2003).

54. Anterior ramus of lacrimal dorsoventral height approximately equal (0), or much narrower (1) than anteroposterior width of ventral ramus of lacrimal (Sereno et al., 1996).

55. Ratio of lacrimal anterior ramus length versus ventral ramus length $0.65 \leq 1.00(0)$, or $<0.65(1)$, or $>1.00$ (2) (Sereno et al., 1996). (UO)

56. Lacrimal does not contact postorbital (0), or bears posterior process that contacts postorbital, excluding frontal from rim of orbit: absent (1) (Sampson et al., 1998).

57. Lacrimal antorbital fossa without (0), or with (1) deep pneumatic recesses in posterodorsal corner of lacrimal (Novas, 1989; Holtz, 1998).

58. Lateral lamina of lacrimal ventral ramus linear and remains posterior to medial lamina (0), or sinuous and protrudes anteriorly beyond medial lamina (1).

59. Lacrimal antorbital fossa small or nonexistent (0), or large, excavates laterally open triangular fossa on lacrimal ventral ramus (1).

60. Lacrimal not dorsally enlarged (0), or with distinct "horn" (= posterodorsal boss or blade) (1) (Rauhut, 2003).

61. Lacrimal ventral process with relatively linear orbital margin (0), or with suborbital process/posterior convexity (1) (Sampson et al., 1998).

62. Postorbital long-axis oriented nearly vertical (0), or anteroventralposterodorsal (1) (Novas, 1989, Carrano et al., 2002).

63. Ventral (= jugal) process of postorbital nearly linear or slightly curved (0), or with distinct suborbital process (1) (Gauthier, 1986, Holtz, 1998).

64. Ventral (= jugal) process of postorbital transversely narrow with triangularcrosssection (0), or broad with U-shaped cross-section (1) (Sereno et al., 1994).

65. Postorbital with stepped-down ventrolateral fossa: absent (0), or present (1) (Sampson et al., 1998, Carrano et al., 2002).

66. Anterior process of postorbital dorsally higher than posterior process (0), or at about same level as posterior process, resulting in T-shaped postorbital (1) (Currie, 1995; Holtz, 1998).

67. Jugal-maxilla overlap length $<50 \%(0)$, or $\geq 50 \%$ (1) total jugal length (Sampson et al., 1998).

68. Anterior process of jugal abuts lacrimal (0), or bears dorsal flange that laterally overlaps ventral process of lacrimal (1) (modified from Sereno et. al., 1994; Carrano et al., 2002).

69. Jugal contacts internal antorbital fenestra (0), or does not contact internal antorbital fenestra, participates in external antorbital fenestra (1), or no participation in external antorbital fenestra (2) (Holtz, 1998; Carrano et al., 2002). (UO)

70. Posterior process of jugal undivided (0), or divided, ventral prong subequal or much shorter than dorsal prong (1), or divided with ventral prong much longer than dorsal prong (2) (modified from Gauthier, 1986; Sereno and Novas, 1993; Sereno et al., 1993; Holtz, 1998). (0)

71. Lateral surface of jugal flat (0), or with low rounded ridge that traverses anterior and posterior processes (1) (Sereno and Novas,1993).

72. Ventral process of squamosal narrow (0), or broad and/or expanded (1) (Rauhut, 2003).
73. Quadratojugal and squamosal contact small (0), or broad (1), or absent (2) (modified from Holtz, 1998; Rauhut 2000,2003). (UO)

74. Quadratojugal and quadrate remain separate (0), or fuse (1) in adults (Holtz, 1994, 1998).

75. Quadrate short or moderately tall and dorsoventrally oriented (0), or tall and posteroventrallyangled so ventral condyle is posterior to dorsal condyle and paraoccipital processes (1) (modified from Rauhut, 2003).

76. Quadrate foramen small and surrounded mostly by quadrate (0), or absent (1), or large and surrounded by near equal shares of quadrate and quadratojugal (2) (modified from Novas, 1989; Holtz, 1998; Carrano et al., 2002; Rauhut, 2003). (UO)

77. Supratemporal fossae widely separated by parietals (0), or in contact posteriorly but separated anteriorly by triangular plate of parietals (1), or confluent so parietals reduced to a sagittal crest (2) (modified from Rauhut, 2003). (UO)

78. Basisphenoid lateral surface not excavated by fossa (0), or excavated by anterior tympanic recess (1) (Rauhut, 2003).

79. Basisphenoidal recess very shallow, poorly developed, or absent (0), or deep and well developed (1) (Rauhut, 2003).

80. Transverse intertuberal lamina of basisphenoid a simple wall (0), or bears small median spur that projects anteriorly along roof of basisphenoidal recess (1).

81. Cranial nerves $\mathrm{X}$ and $\mathrm{XI}$ exit skull laterally through metotic (=jugular) fissure $(0)$, or through foramen/foramina on posterior skull surface lateral to occipital condyle and foramen for cranial nerve XII (1) (Rauhut, 2003).

82. Ventral edge of proximal end of paroccipitalprocess is dorsal to (0), or at same level or ventral to (1) horizontal plane through middle of occipital condyle (modified from Rauhut, 2003).

83. Interorbital braincase elements (i.e., interorbital septum or mesethmoid, orbitosphenoid, sphenethmoid) do not ossify (0), or ossify (1) by adulthood (Novas, 1997; Carrano et al., 2002).

84. Ectopterygoid flange of pterygoid flat $(0)$, or marked by fossa (1) (Gauthier, 1986).

85. Ectopterygoid ventral surface flat (0), or with deep fossa (1), or with fossa and deep groove excavated into body of element from medial side (2) (modified from Rauhut, 2003). (UO)

86. Dorsal edge of anterior tip of dentary wntinuous with mid-dentary (0), or is raised conspicuously relative to middle and posterior parts of dentary (1) (Sereno, 1999a).

87. Dentary tooth count $\leq 18(0)$, or $>18$ (1) (Carrano et al., 2002).

88. Posterodorsal end of dentary without (0), or with (1) socket for surangular prong (Carrano et al., 2002).

89. Posteroventral process of dentary extends further posteriorly than posterodorsal process (0), or subequal in length to posterodorsal process (1) (Sereno, 1999a).

90. External mandibular fenestra small or moderate in size $(0)$, or very large (1) (Gauthier, 1986; Sampson et al., 1998).

91. Splenial without (0), or with (1) foramen (either closed or ventrally open) near anteroventral margin (Rauhut, 2003).

92. Splenial posterior margin forked (0), or straight, not forked (1) (Rauhut, 2003).

93. Angular stops short of posterior end of mandible (0), or reaches posterior end of mandible, blocking surangular from ventral margin of jaw in lateral view (1).

94. Retroarticular process of mandible about same mediolateral width (0), or much broader (1) than mandible anterior to jaw joint (Rauhut, 2003).

95. Serrations on mesial-most premaxillary teeth of 'normal' size and number $(0)$, or are very small and few in number, or wholly lacking (1) (Rowe, 1989; Rowe and Gauthier, 1990).

96. Mesial premaxillary teeth cross-section labiolingually flattened (0), or subcircular (1) or asymmetrical, 'D'-shaped (2) (Rowe, 1989). (UO)

97. Long axis of mesial premaxillary teeth recurved (0), or nearly straight (1) (Rowe, 1989).

98. Maxillary interdental plates remain separate (0), or fuse to each other (1) (Rauhut, 1995; Holtz, 1998).

99. Medial surfaces of maxillary interdental plates smooth (0), or heavily striated/ridged (1) (Sampson et al., 1996, 1998).

100. Maxillary interdental plates relatively tall, broadly exposed (0), or low and partially obscured by lamina of maxilla (1) in medial view (modified from Carrano et al., 2002). 
101. Mesial dentary teeth similar in size (0), or enlarged (1) relative to mid- and distal dentary teeth (Rauhut, 2003).

102. Anterior articular surfaces of cervical and anterior dorsal centra flat or weakly concave (0), or strongly convex, ball-like (1) (Gauthier, 1986).

103. Posterior articular surfaces of cervical and anterior dorsal centra flat or weakly concave (0), or deeply concave (1) (Gauthier, 1986).

104. Anterior articular surfaces of anterior cervical centra circular or taller than wide (0), or wider than tall (1) (Gauthier, 1986; Rauhut, 2003).

105. Post-axial cervical vertebrae without (0), or with (1) pleurocoelsin anterior part of centrum (modified from Gauthier 1986; Rowe, 1989; Rowe and Gauthier, 1990).

106. Post-axial cervical vertebrae without (0), or with (1) pleurocoels in posterior part of centrum (modied from Gauthier 1986; Rowe, 1989; Rowe and Gauthier, 1990).

107. Cervical pleurocoels absent (0), or present as deep ovoid fossae or pockets (1), or present as foramina leading to internal centrum cavities (2). (UO)

108. Internal pneumatic cavities in vertebral centra absent (0), or present with camerate structure (1), or present with camellate structure (2) (Carrano et al., 2002). (UO)

109. Transverse processes of postaxial presacral vertebrae without ventral braces $(0)$, or ventrally braced by centrodiapophyseal laminae (1).

110. Cervical epipophyses absent (0), or are low ridges (1), or elongate, narrow, and project posterolaterally beyond postzygapophyses (2), or strongly developed, and project mostly dorsally above zygapophyses (3) (Holtz, 1994,1998; Novas, 1997). (UO)

111. Cervical epipophyses not anteriorly expanded (0), or with anteriorly directed processes (1) (Sereno, 1999a; Carrano et al. 2002).

112. Cervical epipophyses at level below or even with top of neural spine (0), or dorsal to top of neural spine (1) (modified from Holtz, 1998).

113. Cervical vertebrae without (0), or with (1) epipophysealprezygapophyseal laminae (Coria and Salgado, 1998).

114. Axis lacks pleurocoels (0), or bears pleurocoels (1) (Rowe, 1989).

115. Axis bears a distinct diapophysis (0), or lacks a distinct diapophysis (1) (Rowe, 1989).

116. Axial parapophysis distinct, strongly developed (0), or weakly developed to indiscernible (1) (Rowe, 1989).

117. Axial neural spine and epipophyses/postzygapophyses connected by laminae (0), or widely separated (1) (modified from Sereno et al., 2004).

118. Anterodorsal border of axial neural spine straight-edged or weakly concave (0), or dorsally convex and blade-like (1) (Makovicky and Sues, 1998).

119. Axial neural spine stops posterior to prezygapophyses (0), or extends anteriorly beyond prezygapophyses (1).

120. Axial neural arch lacks pneumatic foramina (0), or with pneumatic foramen/foramina posterodorsal to diapophysis (1).

121. Anterior post-axial cervical centra with rounded or flattened ventral surface (0), or median ventral keel (1) (Makovicky, 1995; Rauhut, 2003).

122. Post-axial cervical prespinal fossae narrow (0), or broad (1) (Coria and Salgado, 1998).

123. Neural spines of post-axial cervicals dorsoventrallyhigh (0), or low (1) (Russell and Dong, 1993; Carrano et al., 2002).

124. Neural spines of post-axial cervicals anteroposteriorly broad (0), or very short (1) (Carrano et al., 2002).

125. Cervical zygapophysespositioned near midline (0), or displaced far laterally away from centrum (1) in dorsal view (Makovicky and Sues, 1998; Holtz, 1998).

126. Post-axial cervical neural arches solid (0), or house pneumatic cavities lateral to neural canal (1).

127. Lateral surface of post-axial cervical arch pedicels solid (0), or pierced by foramen/foramina anteroventral to postzygapophysis (1), or bear triangular, posterior-directed apertures anterior to postzygapophysis (2). (UO)

128. Mid-cervical centrum length $<3$ times (0), or $3<4$ times (1), or 24 times (2) diameter of anterior face (modified from Holtz, 1998; Sereno, 1999a). (0)

129. Cervical neural spines approximately centered over centrum $(0)$, or positioned mostly over anterior half of centrum (1) (Carrano et al., 2002).
130. Cervical ribs remain separate from (0), or co-ossify to (1) their respective vertebral centra in adults (Gauthier, 1986).

131. Cervical ribs stout, relatively blade-like (0), or exceptionally thin posteriorly (styliform) (1) (Holtz 1998).

132. Cervical ribs $<4(0)$, or $\geq 4$ (1) times centrum length (Holtz 1998).

133. Cervical rib heads without signs of pneumaticity $(0)$, or are marked by pneumatic excavations (1) (Harris, 1998; Carrano et al., 2002).

134. Anterior cervical rib shafts proximal part rod-like or blade-like (0), or greatly expanded and flattened (1) (Coria and Salgado, 1998).

135. Cervical and dorsal neural arch surfaces ventral to transverse processes are imperforate (0), or pierced by multiple pneumatic foramina (1).

136. Anterior dorsal vertebrae without (0), or with (1) pleurocoel in anterior half of centrum (Holtz, 1994,1998).

137. Dorsal vertebrae with parapophyses on or close to centrum (0), or with parapophyses that project laterally on "stalks" (1) (Carrano et al., 2002).

138. Hyposphene-hypantrum articulations absent (0), or present (1) on dorsal vertebrae (Gauthier, 1986).

139. Dorsal transverse processes directed laterally, giving rectangular profile in dorsal view (0), or with strongly backswept anterior margin resulting in triangular profile in dorsal view (1) (modified from Rowe, 1989; Rowe and Gauthier, 1990).

140. Transverse processes of dorsal vertebrae anterposteriorly narrow (0), or broad, extending to lateral margin of prezygapophysis (1) (modified from Rowe, 1989; Rowe and Gauthier, 1990).

141. Posterior dorsal vertebral centrum length $<1.33(0)$, or 21.33 (1) times height of anterior articular surface (modied from Rauhut, 2003).

142. Posterior dorsal vertebral centrum length $<2(0)$, or 22 (1) times height of anterior articular surface (Sereno, 1999a).

143. Neural spines of posterior dorsal vertebrae no taller than anteroposteriorly long (0), or substantially taller than anteroposteriorly long (1) (Rauhut, 2003).

144. Vertebra 23 part of dorsal vertebral series $(0)$, or incorporated into sacral series (as dorsosacral 3) (1).

145. Vertebra 24 part of dorsal vertebral series $(0)$, or incorporated into sacral series (as dorsosacral 2) (1).

146. Vertebra 25 part of dorsal vertebral series $(0)$, or incorporated into sacral series (as dorsosacral 1) (1).

147. Vertebra 28 part of caudal vertebral series (0), or incorporated into sacral series ( as caudosacral1) (1).

148. Ventral margin of sacral series relatively straight (0), or exhibits strong dorsal-ward arching (1) (Holtz, 1994, 1998; Sereno, 1999a).

149. Diameter of mid-sacral centra approximately the same (0), or substantially smaller (1) than posterior dorsals and anterior caudals (Holtz, 1994, 1998).

150. Sacral centra remain separate or exhibit limited co-ossification $(0)$, or exhibit full fusion to one another so sutures nearly indiscernible (1) by adulthood (modification of Rowe, 1989; Rowe and Gauthier, 1990).

151. Sacral neural arch elements (transverse processes, arches, neural spines) and sacral ribs of adjacent vertebrae remain separate (0), or fuse to one another by adulthood (1) (Rowe, 1989; Rowe and Gauthier, 1990).

152. Sacral transverse process of at least mid-sacrals remain separate (0) or coalesce to form nearly continuous horizontal sheet in dorsal view (1) by adulthood (Rauhut, 2003).

153. Sacral ribs and transverse processes remain separate (0), or fuse to ilia (1) in adults (Rowe 1989; Rowe and Gauthier, 1990).

154. Ventral surface of caudal centra smooth or bear shallow longitudinal groove (0), or bear narrow, sharp longitudinal groove (1) (Rowe and Gauthier, 1990).

155. Distal ends of transverse processes of anterior caudal vertebrae not expanded (0), or anteroposteriorly expanded (1) (Coria and Salgado, 1998).

156. Hyposphene-hypantrumarticulations absent (0), or present (1) on anterior and midcaudal vertebral arches (Coria et al., 2002).

157. Neural spines of mid-caudal vertebrae rod-like and posteriorly inclined (0), or tall, rod-like, and vertically directed (1) (Rauhut, 2003).

158. Neural arch elements (transverse processes, neural spines) not abruptly reduced in caudal series $(0)$, or reduced in distal caudal vertebrae (1), or reduced in mid-caudal vertebrae (2) (modified from Gauthier, 1986). (O) 
159. Distal caudal vertebral zygapophyses with $<25 \%$ overlap (0), or $25 \%<50 \%$ overlap (1), or $250 \%$ overlap (2) of preceding centrum (modified from Gauthier, 1986; Holtz, 1998; Rauhut, 2003). (0)

160. Mid and distal haemal arches (chevrons) rod-lie or slightly expanded distally (@)or Gshaped (1) in lateral view (Carrano et al., 2002).

161. Anterior processes on proximal end of haemal arches (chevrons) absent (0), or small tubercules (1), or large and projecting (2) (Carrano et al., 2002). (UO)

162. Furcula (=median fusion of clavicles) absent (0), or present (1) (Holtz, 1994,1998).

163. Scapular blade broad and relatively short, ratio of maximum length/ minimum breadth $<10(0)$, or blade narrow and long, ratio of maximum length/minimum breadth 210 (1) (modified from Gauthier, 1986; Holtz, 1994; Rauhut, 2003).

164. Distal end of scapular blade markedly expanded (0), or not expanded (1) (Currie and Zhao, 1993; Carrano et al., 2002).

165. Posterior margin of scapular blade curves over full length (0), or nearly straight over most of length, curves posteriorly only at distal tip (1).

166. Anterodorsal border of acromion process of scapula protrudes conspicuously (@) or has smooth, continuous, high-angle transition to scapular blade (1) (modified from Rauhut, 2003).

167. Anterior margin of scapulocoracoid at scapula-coracoid contact notched (0), or continuous and uninterrupted (1) in adults (Holtz, 1998).

168. Posteroventral process of coracoid not expanded beyond glenoid fossa (0), or expanded beyond margin of glenoid fossa (1) (Sereno et al., 1996).

169. Humerus length $\geq 1 / 3(0)$, or $<1 / 3$ (1) femur length (Novas, 1993).

170. Humerus proximal head flattened $(0)$, or rounded, bulbous, subspherical (1) (Holtz, 1998; Rauhut, 2000).

171. Humerus with anteroposterior sigmoid curvature (0), or is straight (1) in lateral view (Sereno, 1999a; Rauhut, 2003).

172. Humerus shaft torsion absent (0), or present (1) (Holtz, 1998).

173. Humeral distal condyles rounded (0), or flattened (1) (Carrano et al., 2002).

174. Deltopectoral crest extends distally $30 \%<45 \%$ humeral length $(0)$, or $245 \%$ humeral length (1), or is small, only a low triangular eminence (2) (Sereno et al., 1998; Rauhut, 2003). (UO)

175. Radius length $250 \%(0)$, or $<50 \%$ (1) humerus length (Sereno et al., 1998; Holtz, 1998).

176. Radius and ulna distal articular surfaces not enlarged (0), or large and subhemispherical (1).

177. Distal carpals I and II separate (0), or fuse to each other, resulting in single element proximally capping metacarpals I and II (1) (Gauthier, 1986).

178. Distal ends of metacarpals dorsally rounded, smooth $(0)$, or with deep, well developed extensor pits (1) (Sereno et al., 1993).

179. Manual digit I proportions normal, with functional phalanges $(0)$, or digit reduced to sub-conical, blocky metacarpal that lacks distal articular condyles and phalanges (1).

180. Metacarpal I and II contact at proximal bases only (0), or proximal half or more of metacarpal I closely appressed to metacarpal II (1) (Gauthier, 1986).

181. Metacarpal I with symmetrical distal articular condyles (0), or strongly asymmetrical distal articular condyles, medial condyle more proximal than lateral condyle (1) (Rauhut, 2003).

182. Phalanx I-1 length/metacarpal I length $\leq 1.0(0)$, or $>1.0$ (1) (Rauhut, 2003).

183. Manual digit III (0), or manual digit II (1) is longest of the manus (Gauthier, 1986).

184. Manual digit II penultimate phalanx (II-2) length $\leq(0)$, or $>(1)$ length of phalanx II-1 (Rauhut, 2003).

185. Manual digit III penultimate phalanx (III-3) length $\leq(0)$, or $>(1)$ length of each of the more proximal digit III phalanges (Rauhut, 2003).

186. MetacarpalIV subequal to metacarpal III (0), or much smaller than metacarpal III (1) or absent (2) (Gauthier, 1986). (0)

187. Manual digit IV with $>1(0)$, or $\leq 1$ (1) phalanx (modified from Gauthier, 1986; Rauhut, 2003).

188. Manual digit $\mathrm{V}$ with prominent metacarpal and $\geq 1$ phalanx $(0)$, or is at most a vestigial metacarpal that lacks phalanges (1), or is absent (2) (Gauthier, 1986). (0)
189. Pelvic bones remain separate (0), or co-ossify with one another (1) by adulthood (Rowe, 1989; Rowe and Gauthier, 1990).

190. Ilium anteroposterior length shorter (0) or about as long or longer (1) than femur (Holtz, 1998).

191. Dorsal margin of ilium dorsally convex and obviously curved (0), or relatively linear/angular (1) (modified from Carrano et al., 2002).

192. Preacetabular process of ilium does not extend past pubic peduncle (0), or extends anteriorly well past pubic peduncle (1) (Gauthier, 1986; Carrano, 2000).

193. Preacetabular process of ilium stout and thick (0), or relatively thin and blade-like (1).

194. Ventral rim of preacetabular process of ilium relatively horizontal (0), or with ventral expansion or 'hook' (1) (modified from Gauthier, 1986; Sereno et al. 1994).

195. Supraacetabular crest of ilium a weakly developed ridge or raised shelf $(0)$, or flares lateroventrally to form hood-like overhang that hides anterodorsal half of acetabulum in lateral view (1).

196. Brevis fossa of ilium narrow (0), or broad (1) posteriorly (Sereno et al. 1994, 1996).

197. Ilium postacetabular length $\leq(0)$, or $>(1)$ acetabulum width (1) (Forster, 1999; Carrano, 2000; Carrano et al., 2002).

198. Posterior margin of ilium posteriorly convex or squared off $(0)$, or concave, notched, or indentated (1) in lateral view (Sereno, 1999a),

199. Ilium with M. iliofemoraliisfossa that reaches posterior rim of bone (0), or stops short of bone's posterior margin, resulting in distinct rim on lateral surface of postacetabular process (1) (modified from Rowe, 1989).

200. Pubic peduncle of ilium size approximately equal to (0), or much greater than (1) ischial peduncle (Sereno et al., 1994).

201. Anteroposterior length of pubic peduncle of ilium $<2$ times $(0)$, or $\geq 2$ times (1) mediolateral width (Gauthier, 1986; Carrano, 2000; Carrano et al., 2002).

202. Pubic peduncle of ilium projects ventrally about as far as $(0)$, or much further than (1) ischial peduncle (Gauthier, 1986; Holtz, 1998).

203. Pubic peduncle of ilium with single distal facet (0), or two facets separated by $\mathrm{ki} i$, resulting in anterior and ventral-oriented pubic contacts (1) (modified from Sereno et al., 1998).

204. Ilium-pubis articulation abutting (0), or with deep peg-in-socket (socket in pubis) connection (1) (Sampson et al., 2001).

205. Proximal pubic plate ventromedial to obturator foramen solid (0), or with pubic fenestra (1), or pubic fenestra and obturator foramen intersect to form obturator notch (2) (Rowe, 1989; Rowe and Gauthier, 1990). (0)

206. Mediolateral width of pubic midshaft $225 \%$ (0), or $<25 \%$ (1) overall shaft length.

207. Axis of pubic shaft straight or curves anteriorly (0), or curves ventrally, resulting in anterior bowing (convex anterior, concave posterior) of shaft in lateral view (1) (Rowe, 1989).

208. Medial lamina of pubis that reaches distal tip of shaft (0), or stops short of distal tip of pubic shaft, resulting in short median separation between distal tips of pubes (1).

209. Distal tips of pubes with median contact $(0)$, or without median contact (1) (modified from Holtz, 1998; Rauhut, 2000).

210. Distal tip of pubis lacking substantial anteroposterior enlargement (0), or enlarged $2<3$ times (1) or $\geq 3$ times (2) anteroposterior width of pubic shaft (modified from Rauhut, 2003). (0)

211. Distal expansion of pubis continuous with or expanded laterally beyond margin of shaft $(0)$, or medially inset from lateral edge of pubic shaft (1).

212. Distal tip of pubis elongate rectangular or subequant (0), or subtriangular (1) in distal view (modified from Rauhut, 2003).

213. Ischium length $>2 / 3(0)$, or $\leq 2 / 3$ (1) the length of pubis (Gauthier, 1986).

214. Ischial antitrochanter small, indistinct $(0)$, or large and protrudes anterolaterally into acetabulum, giving 'notched' profile to posteroventral margin of acetabulum (1) (Rowe and Gauthier, 1990; Sereno, 1999a).

215. Proximal plate of ischium solid or with fully enclosed ischial foramen (0), or ischial foramen ventrally open, cutting off obturator process from anterior process of ischium (1) (modified from Rauhut, 2003).

216. Obturator process of ischium continuous with ischial shaft $(0)$, or distally separated from ischial shaft by notch (1) (Rauhut, 1995; Carrano et al., 2002). 
217. Distal tip of ischium not anteroposteriorly enlarged (0), or enlarged $\leq 3$ times (1), or $>3$ times (2) minimum anteroposterior width of ischial shaft (modified from Novas, 1993; Rauhut, 2003).

218. Femoral head oriented anteromedially (0), or strictly medially (1) when distal condyles set perpendicular to axial column (Novas, 1991; Holtz, 1994).

219. Femoral head directed slightly ventrally (0), or horizontally or slightly dorsally (1) (Harris, 1998).

220. Femoral head relatively continuous with posterior surface of femur (0), or set off by well defined oblique ligament groove on posterior surface, giving 'hooked' proximal profile to femoral head (1) (Rauhut, 2003).

221. Femoral dimorphism not present (0), or present, expressed in muscle scars, attachments, and processes ('robust' versus 'gracile' morphs) (1) (Rowe and Gauthier, 1990).

222. Femoral anterior trochanter a low ridge or tuberosity (0), or a conical spike or pyramidalprominence (1), or a mediolaterally compressed flange ( $=$ aliform process) projecting anteriorly from femur (2) (modified from Gauthier, 1986; Carrano, 2000). (UO)

223. Femoral anterior trochanter does not reach proximally to mid-point of femoral head (0), or reaches proximally at least to mid-point of femoral head (1) (modified from Gauthier, 1986).

224. Femoral trochanteric shelf large and pronounced (0), or expressed as low mound or swelling distolateral to anterior trochanter (1) in adults (modified from Carrano et al., 2002).

225. Medial epicondyle of femur weak (0), or strongly developed ridge (1), or hypertophied and flange-like (2) (Forster, 1999).

226. Anterior surface of femoral distal end flat or convex (0), or with broad, shallow, depression bordered medially by medial epicondyle (1) in adults (Rauhut, 2003).

227. Tibiofibular crest of femur smoothly continuous with lateral dista condyle (0), or sharply demarcated from lateral distal condyle by sulcus or concavity (1) (Rowe, 1989).

228. Femoral popliteal fossa smooth (0), or traversed by infrapopliteal ridge between medial $(=$ tibial) distal condyle and tibiofibularcrest (1) in adults.

229. Anteroposterior length of cnemial crest of tibia $<(0)$, or $\geq(1)$ width across proximal (=femoral) condyles of tibia.

230. Lateral surface of cnemial crest of tibia flat $(0)$, or excavated by longitudinalfossa, giving tibia laterally 'hooked' profile in proximal view (1) (modified from Sampson et al., 1998).

231. Proximal condyles of tibia continuous (0), or separated by cleft along posterior rim of tibia in proximal view (1) (Rauhut, 2003).

232. Anterior tip of cnemial crest of tibia not expanded (0), or proximodistally expanded (1) (Forster, 1999).

233. Fibular crest (= crista fibularis) of tibia absent (0), or low ridge extending distally from proximal tibia (1), or distally placed, flangelike, separated from proximal tibia (2) (Gauthier, 1986; PerezMoreno et al., 1993; Rauhut, 2003).

234. Tibia and fibula spaced apart (0), or closely appressed (1) through most of shafts' length (Gauthier, 1986; Holtz, 1994).

235. Distal end of tibia anteriorly flat or weakly convex (0), or with broad anterior fossa bearing oblique (proximolateral to distomedial) proximal border (1) (modification of Rauhut, 2003).

236. Tibia distal profile subequant to subrectangular $(0)$, or subrectangular with small posterolateral extension (1), or subtriangular with large posterolateral expansion (2) (modified from Gauthier, 1986; Sereno et al., 1994; Rauhut, 2003). (1). (0)

237. Medial side of proximal end of fibula flat (0), or excavated by longitudinal groove (1) (modified from Rowe, 1989; Rowe and Gauthier, 1990; Rauhut, 2003).

238. Medial side of proximal end of fibula flat $(0)$, or with oblique (posteroproximal to anterodistal) ridge that overlaps proximal part of medial fibular groove (1) (Rowe, 1989; Rowe and Gauthier, 1990; Rauhut, 2003)

239. Fibular M. iliofibularis insertion weak or indiscernible (0), or distinct small tubercle (1), or large anterolaterally projecting tubercule or process (2) (Rauhut, 2000; Carrano et al., 2002). (0)

240. Anteroposterior midshaft width of fibula $>30 \%(0)$, or $530 \%$ (1) anteroposterior width of proximal end of fibula (Sereno, 1999a).

241. Fibula does not overlap astragalus (0), or bears medial flange that overlaps part of the ascending process of astragalus (1) (Rowe, 1989; Rowe and Gauthier, 1990).

242. Fibula separate from (0), or co-ossifies with (1) ascending process of astragalus of adults (Carrano et al., 2002).
243. Fibular facet on proximal surface of astragalus large, intersects posterior rim of astragalus $(0)$, or large, does not reach posterior rim of astragalus (1), or small subtriangular fossa on anterolateral corner of proximal surface of astragalus (2). (0)

244. Ascending process of astragalus height $<(0)$, or $\geq(1)$ height of main body of astragalus (Carrano et al., 2002).

245. Ascending process of astragalus positioned near center of astragalus proximal surface (0), or near anteroproximal margin of astragalus (1).

246. Tibial facet of astragalus shallow and mostly medial to base of ascending process (0), or deep and extends posterior to base of ascending process (1) (Novas, 1989, 1996; Carrano et al., 2002).

247. Ascending process of astragalus robust, pyramidal prominence (0), or anteroposteriorly flattened (1) (Sereno et al., 1994).

248. Anterior surface of astragalussmooth, not grooved (0), or traversed by horizontal groove (1) (Gauthier, 1986).

249. Astragalus and calcaneum remain separate (0), or fuse to each other (1) by adulthood (Rowe 1989).

250. Astragalus and tibia remain separate (0), or fuse to each other (1) by adulthood (Rowe, 1989).

251. Calcaneum without tibial facet (0), or with small tibial facet on posteromedial corner (1), or with large tibial facet covering most of posterior surface and reaches nearly to lateral edge of calcaneum (2) (Sereno et al., 1996; Rauhut, 2003). ( $O$ )

252. Distal tarsal III remains separate (0), or fuses to (1) metatarsal III by adulthood (modified from Rowe, 1989; Rowe and Gauthier, 1990).

253. Distal tarsal IV round or sub-rectangular (0), or with large notch in posterlateral comer (1).

254. Metatarsal I contacts ankle joint ( 0 ), or does not contact ankle joint (1) (modification of Gauthier, 1986; Rauhut, 2003).

255. Metatarsal I length $250 \%(0)$, or $<50 \%$ (1) length of metatarsal II (Gauthier, 1986).

256. Metatarsal I positioned on medial surface (0), or on ventral/plantar surface (1) of metatarsal II (Holtz, 1998).

257. Proximal ends of metatarsals II and III remain separate (0), or co-ossify to each other (1) by adulthood (Rowe, 1989).

258. Mediolateral width of metatarsal II shaft approximately $=$ widths of III and IV (0), or < width of IV and both < III (1) (Carrano et al., 2002).

259. Proximal end of metatarsal III does not back ventral side of metatarsals II and IV (0), or backs metatarsals II and IV ventrally, resulting in "T"-shaped proximal profile ("antarctometatarsus") (1).

260. Proximal end of metatarsal III not ventrally enlarged (0), or with ventral boss protruding beyond plane of metatarsal shafts (1).

261. Metatarsal V with distal articular surface (0), or lacks distal articulation (1) (Gauthier, 1986; Rauhut, 2000).

262. Metatarsal V shaft round and straight (0), or mediolaterally flattened and distal end angles dorsally (anteriorly) (1) (modified from Gauthier, 1986; Rauhut, 2003).

263. Pedal unguals with single lateral groove (0), or two lateral grooves (1) (Sampson et al., 2001; Novas and Bandyopadhyay, 2001).

264. Ungual of pedal digit II symmetrical (0), or asymmetrical (1) (Carrano et al., 2002).

APPENDIX 2. The scorings of the 264 characters for the 4 outgroup and the 30 ingroup taxa used in phylogenetic analysis. We coded Berberosaurus liassicus and the basal abelisauroid Spinostropheus gautieri into a matrix based upon that of Tykoski (2005). 0, 1, 2: character states; ?: could not be observed or missing data. Multistate characters in parentheses within a single taxon were treated as polymorphisms.

\section{Marasuchus}

???????????????????????????????????????????????????????????????

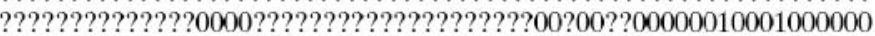
00000????000?00100000000000000?00000?0??0??00000?00??????????? $00000000000100000010000001000000 ? 000 ? 00 ? 00000000 ? 00000000100000$ 0000000001000

Lesothosaurus

0000000100000000000?000?000000000000??0000000000000000100?10000 $0000 ? 000000000000000000000000000200000000000000000011 ? 0 ? 0000100$ 0000????000000000??110000?0000000???00(0,1)00?000000000000000000 $0001010000000000000100100000000000021 ? 000000000100000000 ? ? ? ? 0 ? ?$ $01000000000 ? ? 00$ 
Scutellosaurus

0????00?00????000????0?????0?0????????0?00???????????????????? ??????????????????????000?0?????0?000?00?000000000????????00000 $0000 ? ? ? ? 0000000000 ? 11000000000 ? 0 ? 00 ? 0100 ? 000000000 ? 0 ? ? ? ? ? ? ? ? ? ? 0$ $11100001000000021001000000 ? 0000020 ? 0 ? 000 ? 00010000010000110000 ? 0$ ?0000000??0?

Plateosaurus

$0000000100100000001000100010000 ? 0000000000110000000010000000000$ 000001000000000000000000010100000100000000000110000000000001000 000000000001000000001000000000000000000000000101000000101000000 $0000000000000000000000000001000000 ? 0000000000000000000000000000$ 00000000000

Herrerasaurus

$00000001000000 ? 000000001000000101000 ? ? 0000000000000000000000000$ 000000111000?0000?000?000000?000000?00000000?110000000000000000 $0000 ? ? ? ? 000100001000000000100 ? 0120 ? ? 0010 ? ? 000000000100010101110$ 000000000000000000002000000000000000000000000000010000000000000 000000000000

\section{Eoraptor}

$00000010011000 ? 0001 ? 0000000001010000 ? ? 010001000 ? 000110000010000$ 00010211?0?000?00?????????0??0?000???000?000??1000???0????01000 000??000000?00000001?00????00????000000??0000100000100100101110 000100?10?0000010100000000?100???0??00?0??0?0010??0????0??????? $0000 ? 0001000$

\section{C.bauri}

$0101101010110101111010011110010100001 ? 0100111000000110200010000$ 000001210000?0?1??000?110?0??001110?1?01?1110120000110110001001 21011?0001011111001110011111000100010010?0000100001100111111121 $0111011111000101111110111011001110 ? 111101101111111 ? 100010011101$ $111 ? 10 ? 11000$

\section{C.rhodesiensis}

01011010111101011110100?111001010000100100111000000110200010000 $000001 ? 100000011100001110 ? 0 ? ? 0011100110 ? ? 111 ? 120000110110001001$ 210111000?011111001110011111000110110010?0000100001100111111121 0111011111000101111100?110110011(1,2)01111?0110111111111020100?1 111111110111000

\section{"C".kayentakatae}

$010110101111010111110000111001010100100300111000000110200110 ? 00$ $00000221000000111010 ? 1100101 ? 10111 ? ? ? 10 ? ? 1110120000110110001001$ 210111?0?101?????01111011??1??0????100111000???0???1???????10?1 0?11?1111100010?111110011??1001?10?1111011011111111102010011111 111110011100

\section{Segisaurus}

????????????????????????????????????????????????????+??????????

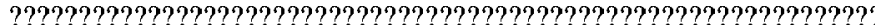
????1?????0?111???111??????1100??0111011200?1100????????1?????1 ?????11????0???11111100?10?00?1?10??1??0??011??112???????????? $1120 ? 0 ? ? 100$ ?

Shake-N-Bake

0??????????????????????????10?0????????????????????????????

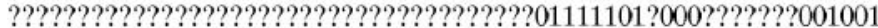
22011???01011111?011100111110001?????????0??????????????????1 0?11?111010001?111??????10???011(1,2)011?110110111111??102010011 1111??110?????

\section{Zupaysaum}

01111??????????1??1000011?1001010110??03001?10000001102011100?0

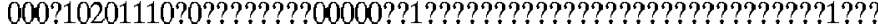

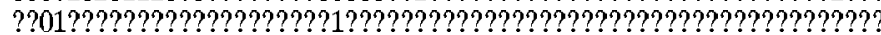

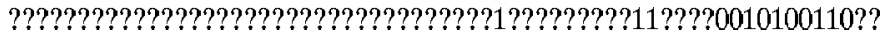
???????????

\section{Liliensternus}

0??????????????????????????0?10?00???????????????????????????0

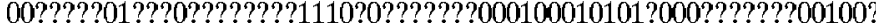
010???0001011110?????00?????0?0??????010?000010000?1??????????? 011101111000010?1111101110?1001?10?0?0?01101?11??100?0010001?0? ?????001??0?
Dilophosaurus

$01111000101101011111001111000000010011020011100 ? ? 00110000110000$ 00?01?201??000110?00??10000??001?0?0(0,1)10111110120000110110000 0000000??000101111010111?0?11110101101?001??0000100001100111?11 12101110111000001011111101?101200111011?1?011011111111?0111001? $01 ? 1111 ? 0001100$

Elaphrosaurus

?????????????????????????????????????????????????????????????

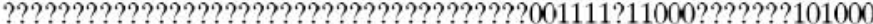
0201????00011110011111011110000?1???0????1011112?0?1?????????? ?111?1111010001?1????????002001?20111??01101?02??1?????1???1010 ????0111????

Ceratosaurus

001101000011101001100011000000000110011000211000000110001111000 $00110220101111110 ? 1110000 ? 0110 ? 02010000101122130001000111000000$ $0001 ? ? 10001111001111111111110011001 ? 010110001000 ? ? ? 1001 ? ? ? ? 1 ? 21$ $10111011 ? 010001111002 ? ? 0101200112001111111011121121102010111120$ $1 ? ? ? 0011 ? ? 0$ ?

Ilokelesia

??????????????????????????????????????????????????????1?????01

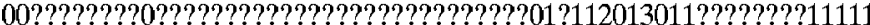

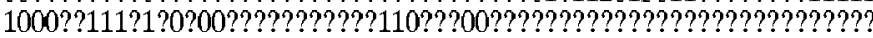

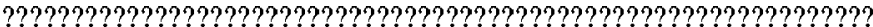
??????????11

Xenotarsosaurus

????????????????????????????????????????????????????????????)

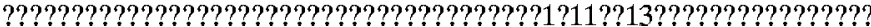
?0???????1?????????????????????????????????????????????????????

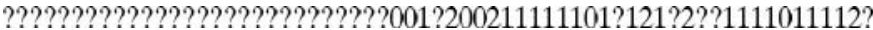
????????????

Aucasaurus

$1011 ? 1 ? ? 0 ? 1 ? 1 ? ? 001 ? 021 ? ? 00 ? 0 ? ? 10 ? 1000 ? ? ? ? ? ? 1 ? ? 21 ? ? ? 1111 ? ? 0 ? 0 ? ? ?$

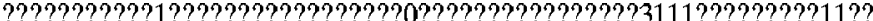

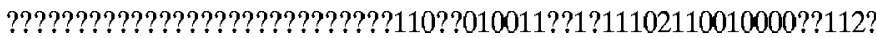

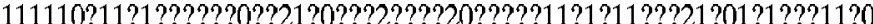
$111100 ? 110 ?$ ?

Abelisaurus

101?110?001?10?00??02111??00?0101100??201121010101111??10?00111

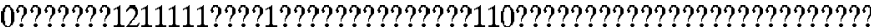

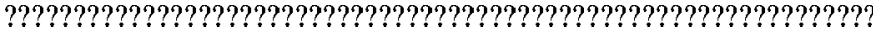
??????????????????????????????????????????????????????????????? ???????????

\section{Carnotaurus}

$10110101001110 ? 001102101000000101100 ? ? 2011210121111111110000111$ 0111101012111111??11??001111?0102011000111122131111000111111111 10001011111101001111111110??111???0?01111111101211?01?00????121 $11111011101000 ? 1101021100012000$ ?2012111?11?1???102??????????? ????????????

Majungatholm

1011010?001110100?102111000000101100012011210111111111110000111 0111101012 ? $111112011100011111010201100011112213011100 ? ? ? ? 111111$ 1000??11??11??001?11111?1???001??01?01???1111012??????????????

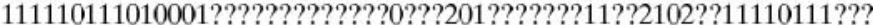
?????0?1??11

\section{Masiakasaurus}

0???????????????0102??1?101?000001000???????????????????????) ??????????????????????0011100?????101101?(0,1)(0,1)2113011??????? ?011111010??1110?1??11?????0011???00011??????????11??2?????????

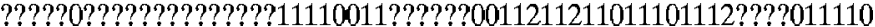
$11112 ? ? ? ? ? 01 ? ? ? ? 1 ?$

\section{Noasaurus}

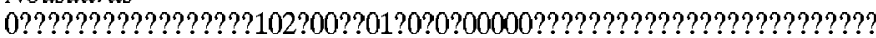

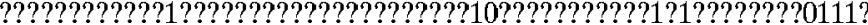

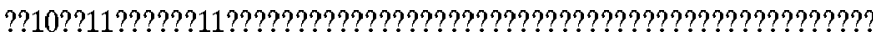

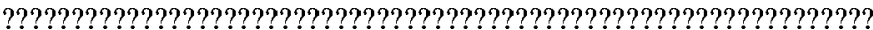
?????1?????? 
Tomosumits

00110000101?10?00?1100210000000000100-????????????111001011000

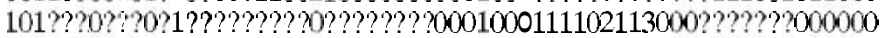
0000???0110100001?????????00000??01?? ?????0110110?1011?1??2120 ?01110100010100000101100001??????????01102?121011002010110020 ????0002????

\section{Baryonyx}

01???0011011?000011?????11?0?0?0????21100???00000 11110101 10?0 00? ?0??1??0?20110?1???1 100011?"1110011111102?13011 00100000000 0000?01001010000_?????????????'00?0?0??1?0110_1?" ?????1?"???0

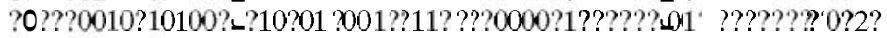
???????????

\section{Irritator}

01110?????11??????10102????010100200??1000100000000111001011010 001001211?00??110?1???????????????????????????????????????????? ???????????????????????????????????????????????????????????+ ???????????????????????????????????????????????????????????? ??????0????

\section{Cristatusaurus}

$0111000110110000011000211110101202002 ? 100010000000011110 ? ? 1 ? 0 ? ?$

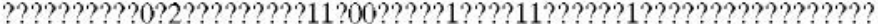

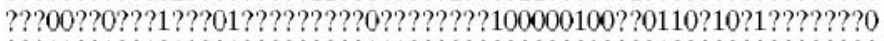
00011?010?1?10??10???????111??????0?????0????1?????????????? ??????0????

\section{Dubreuillosaurus}

0?11100?001??00???1100210?001000021001?????1?0000011100?110000

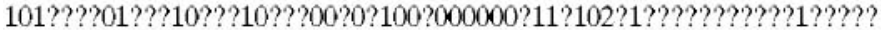

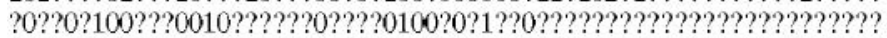

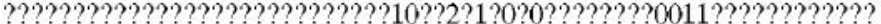
???????????

\section{Eustreptospondylus}

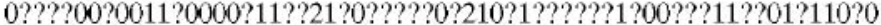
$1 ? 1 ? ? ? ? ? 1 ? ?, 1011 ? 110 ? ? 00 ? 0 ? ? ? ? ? 00000011111021130 ? 00 ? 011 ? ? 10 ? 00 ?$ ?00?????10100101????0??????0?0?????1??????0?01??????????????

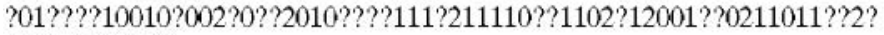
?????000??0?

\section{Allosaurus}

$0011000100100000001000110000100000101010111000 \infty$ $0010112011000211011012000001001001000110102110 \infty$ $00000010010100001011100000000002121 \_1000100010 \infty$ 101110010011100210102010011111102 11_0001102111 $\infty$ 111100001100

\section{Ornitholestes}

$0000000 ? 001000 ? 001100011000011000201 ? ? 00001 ? ? ? 00000110001110000$ $000 ? 0$ ? $10010002 ? ? ? ? 1 ? ? 2000001 ? ? 11 ? 0 ? ? ? 0111002 ? 13000 ? ? ? ? ? ? ? 10000$ ? ?000????00010011?01110000?0?0??2212?????0?00010000??011??112120 $101100010011000211 ? 0 ? ? ? 00100 ? ? ? ? ? ? ? 1 ? 0 ? ? ? ? ? ? ? ? ? ? ? ? ? ? ? ? ? ? ? ? ? ? ?$ ?????000????

\section{Berberosaurus}

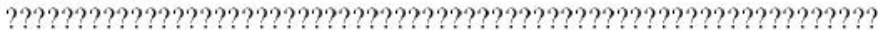

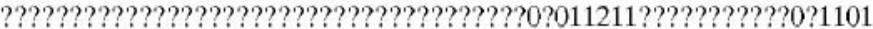

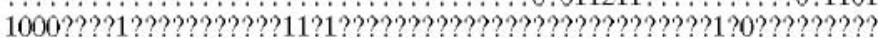

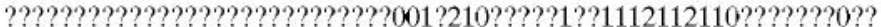
???????????

\section{Spinostropheus}

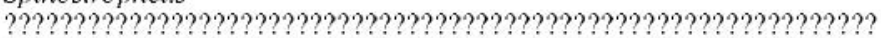
?????????????????????????????????????0111(0,1)2?13001?????????1 $0011000 ? ? 1 ? 111 ?+1 ? ? 1 ? ? ? ? ? ? ?(0,1) ? ? ? ? ? ? ? ? ? ? ? ? ? ? ? ? 0 ? ? ? ? ? ? ? ? ? ? ? ?$

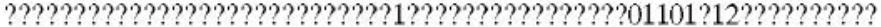
???0?????????????

APPENDIX 3. List of unambiguous synapomorphies of each node in Fig. 8. The first number refers to the character and the second number (in brackets) to the derived state. The homoplastic synapomorphies are in italic. Multiple numbers and arrows indicate transition between multiple states of a character, or indicate reversals. Synapomorphies preserved in known specimens of Berberosaurus are in bold. We recognize that only node-defined clades can technically bear diagnoses, and that synapomorphies listed for stem-defined clades apply to the most basal node on the lineage.

Tetanurae: 29(1), 34(1 $\rightarrow 2), 57(1), 69(2 \rightarrow I), 81(1), 102(1), 117(1)$, $180(1), 186(1 \rightarrow 2), 218(1), 219(1), 223(1), 243(1 \rightarrow 2), 251(1 \rightarrow 2)$.

Avetheropoda: $36(1), 77(0 \rightarrow 2), 159(1 \rightarrow 2), 160(1), 161(1 \rightarrow 2), 190(I)$, 201(1), 215(1).

Spinosauroidea: $23(1 \rightarrow 2), 54(1), 174(1), 175(1)$.

Ceratosauria: 106(1), 118(1), $119(1), 131(1), 139(1), 140(1), 150(1)$, 151(1), 152(1), 167(1), 189(1), 191(1), 196(1), 221(1), 227(1), 228(1), 238(1), 249(1).

Coelophysoidea: 2(1), 5(1), 9(1), 14(1), 16(1), 17(1), 25(1), 26(1), 37(1), $95(1), 101(1), 110(3 \rightarrow 2), 115(1), 116(1), 203(1), 209(1), 222(2 \rightarrow 1)$. Coelophysidae: $71(1), 72(1 \rightarrow 0), 127(0 \rightarrow 2), 142(1), 199(1), 241(1)$.

Ceratosauroidea: 144(1), $148(1), 171(1), 204(1), 259(1)$

Neoceratosauria: 137(1), 149(1), 172(1 $\rightarrow 0), 224(I \rightarrow 0), 239(1 \rightarrow 2)$, $251(I \rightarrow 2)$.

Abelisauroidea: 113(1), 126(1), 127(1), 135(1).

(Berberosaurus + Xenotarsosaurus + Abelisauria) clade: 124(1).

(Xenotarsosaurus + Abelisauria) clade: 242(1), 250(1).

Abelisauria: 224(I).

APPENDIX 4. Phylogenetic taxonomy.

\begin{tabular}{|c|c|c|c|c|c|}
\hline \multirow{2}{*}{ Taxon name } & & & \multicolumn{3}{|c|}{ Reference taxa } \\
\hline & \multicolumn{2}{|c|}{ Phylogenetic definition } & $\mathrm{A}$ & & $\mathrm{B}$ \\
\hline Abelisauria Novas, 1992 & Novas, 1997 & Node & Noasaurus & and & Carnotaurus \\
\hline Abelisauridae Bonaparte and Novas, 1985 & Sereno, 1998 & Node & Abelisaurus & and & Carnotaurus \\
\hline Avetheropoda Paul, 1988 & Padian et al., 1999 & Node & Allosaurus & and & Aves \\
\hline Ceratosauria Marsh, 1884 & Rowe, 1989 & Stem & Ceratosaurus & than & Aves \\
\hline Ceratosauroidea Bonaparte, 1991 & Sereno, 1998 & Stem & Carnotaurus & than & Coelophysis \\
\hline Coelophysidae (Nopsca, 1928) & Holtz, 1994 & Node & Coelophysis & and & Syntarsus \\
\hline Neoceratosauria Novas, 1992 & Holtz, 1994 & Node & Ceratosaurus & and & Carnotaurus \\
\hline Neotheropoda Bakker, 1986 & Holtz, 1998 & Node & Ceratosaurus & and & Aves \\
\hline Noasauridae Bonaparte and Powell, 1985 & Wilson et al., 2003 & Stem & Noasaurus & than & Carnotaurus \\
\hline Spinosauroidea (Stromer, 1915) & Sereno, 1998 & Node & Spinosaurus & and & Torvosaurus \\
\hline Tetanurae Gauthier, 1986 & Gauthier, 1986 & Stem & Aves & than & Ceratosaurus \\
\hline
\end{tabular}

Status of names as either node- or stem-based definitions indicated. Reference taxa for node-based names presented in format of, "Taxon A and Taxon B", indicating clade encompasses most recent common ancestor of Taxon A and Taxon B and all of its descendants. Reference taxa for stem-based names presented in format of, "Taxon A than Taxon B", indicating lineage includes Taxon A and all taxa more closely related to Taxon A than to Taxon B. Original use of name is given under "Taxon Name". First taxon-based phylogenetic definition for the name is given under "Phylogenetic Definition". We recognize the validity of clade names based upon their first stable, ancestry-based definition in most cases. In other words, the first published node-based or stem-based name definition for a clade is recognized whenever possible. 